\title{
The economics of transition pathways: A proposed taxonomy and a policy experiment
}

\author{
Kerstin Hötte $\mathrm{a}^{\mathrm{a}, \mathrm{b}, *}$ \\ ${ }^{a}$ Bielefeld University \\ ${ }^{b}$ Paris-1 Sorbonne Panthéon
}

\begin{abstract}
Pathways of transition differ across countries, industrial sectors, firms and technologies, but little is known about the reasons for these differences and macroeconomic consequences. I show theoretically how differences in transition patterns and macroeconomic side effects can be explained by the characteristics of competing technologies. Competing technologies are characterized by their relative superiority in an exogenous socio-technical landscape, their relative maturity and cross-technology interactions in the process of specialization. These characteristics are linked to the multi-layer perspective of transition theory and build the conceptual basis of technology in the macroeconomic agent-based model Eurace@unibi-eco. It is shown that the characteristics can be an explanation for heterogeneous transition pathways. Policy may alter the exogenous landscape conditions that surround technological competition. It is shown how different market-based instruments can be used to accelerate and stabilize a transition process. Taxes and subsidies perform differently conditional on the characteristics of competing technologies.
\end{abstract}

Keywords: Technological transition, multi-level perspective, technological knowledge, learning, climate policy, agent-based model JEL: O11, D83, O33, Q55, Q58, C63

\section{Introduction}

The transition to carbon-neutral technologies is needed to reduce the risk of crossing irreversible tipping points in the climate system (cf. IPCC, 2018; Steffen et al., 2018), but little is known about possible transition pathways and potential

* Corresponding author

Fakultät für Wirtschaftswissenschaften, ETACE, Postfach 1001 31, 33501 Bielefeld kerstin.hoette@uni-bielefeld.de

This paper is published as: Hötte, Kerstin. "The economics of transition pathways: A proposed taxonomy and a policy experiment." Environmental Innovation and Societal Transitions 36 (2020): 94-113. DOI: https://doi.org/10.1016/j.eist.2020.05.001

Email address: kerstin.hoette@uni-bielefeld.de (Kerstin Hötte) 
(macro)economic consequences. Technology transitions are processes in which an emergent, entrant technology diffuses and replaces the prevalent technological solution (Geels, 2002). Empirically observed diffusion and transition patterns are diverse and differ across technology types, countries, industries and firms (Comin et al., 2006; Geels and Schot, 2007; Adner and Kapoor, 2016; Vona et al., 2015; Geels et al., 2016). Purpose of this paper is to explain these differences using a characterization of competing technologies and a simulation experiment with the macroeconomic agent-based model (ABM) Eurace@unibi-eco.

The characterization is based on the multi-level perspective (MLP) (Lachman, 2013; Köhler et al., 2019) and the typology for different transition pathways proposed by Geels and Schot (2007). MLP decomposes a socio-technical system into a landscape, regime and niche level. The landscape captures external conditions such as resource prices, regulation or preferences. A technological regime is determined by the dominant technological solution to fulfill a societal function. It is stabilized dynamically by incremental innovation and co-evolving norms, institutions, infrastructure and know-how. If the landscape changes, the regime may come under pressure. This opens windows of opportunity for emergent niche technologies to challenge the regime if they are sufficiently superior given the new landscape conditions. Geels and Schot (2007) elaborated conceptually how the shape of transition pathways depends on the timing and nature of cross-layer interactions.

In this paper, I introduce an economic operationalization of these concepts that links MLP to formal economic modeling. I focus on the economic dimension of transitions which enables the study of broader (macro)economic consequences (e.g. transition costs and disruptions in the market structure).

Competing technologies are characterized by cumulative stock variables, exogenous and interactive properties. The entrant technology is a radical innovation that is technically superior because it allows its users to overcome a technical limitation of the incumbent technology. The economic valuation of superiority is an exogenous property because it is beyond the direct influence of technology adopters and users. It is an inherent feature of a specific technology type but whether it is economically valuable depends on the landscape. Stock variables reflect the relative maturity of a technology. The incumbent technology benefits from larger endowments of supporting factors accumulated by research, learningby-doing and investments. If technologies are similar, accumulated supporting factors needed to operate the incumbent are transferable to the utilization of the entrant technology (cf. Boehm et al., 2016; Jaffe and De Rassenfosse, 2017). Transferability is an interactive property because it affects the relative pace of technological specialization. It is related the disruptiveness of technological change (Tushman and Anderson, 1986).

These characteristics are reflected in the modeling of technology in the macroeconomic ABM Eurace@unibi-eco (Hötte, 2019b). The model is used to simulate a technology race between an incumbent conventional and a green entrant technology. Transitions are driven by the adoption and learning behavior of heterogeneous firms. It is shown that the shape of transition pathways can be explained by the characteristics of technologies. Macroeconomic side effects and 
disruptions in the market structure differ across pathways.

Policy can change the external landscape conditions in favor of the entrant. In an experiment, three market-based policies are tested. A tax on the use of conventional technology (e.g. a carbon tax) makes the utilization of the entrant technology relatively cheaper. An investment subsidy reduces the price of green capital. A price support reduces the price for consumer goods produced with green machinery. Capital and input prices are exogenous to users and reflect landscape conditions associated with the availability of resources. The price support is analog to consumers' higher willingness to pay for green products.

It is shown that policy may reinforce and stabilize an ongoing transition process, but increase technological uncertainty if the economy is locked in. Interactions between policies and technological characteristics reveal qualitative differences in the way how instruments operate. For example, the consumption subsidy is only effective if the two technologies are sufficiently similar. In contrast, the tax works well for dissimilar technologies and the investment subsidy is least sensitive to the similarity.

The proposed model offers an explicit, formal representation of economic dynamics that underly transition processes. Modeling sustainability transitions makes it possible to draw inferences from complex dynamics, to execute systematic (policy) experiments and to facilitate the societal and scientific discourse (Holtz et al., 2015; Moallemi and de Haan, 2019). This study may improve the economic understanding of transition pathways, their drivers and side effects. This is crucial for the development of policies conditional on available technology options. The evaluation of economic side effects may facilitate an informed debate about sustainability transitions (Rosenbloom, 2017; Holtz et al., 2015) and to address resistance to change (Watson, 1971). Moreover, the characterization of competing technologies offers a theoretical basis for empirical work. This study is limited to diffusion at the production side and focused on the economic dimension of transitions.

This work contributes mainly to three branches of literature. First, it is a theoretical approach to formalize concepts of MLP within a comprehensive macroeconomic model. MLP is one of the key analytical frameworks of transition theory (Lachman, 2013; Köhler et al., 2019). Existing modeling approaches to MLP are largely conceptual or very application-specific, partial models (see Köhler et al., 2018, for a review). Interactions between transition research and economics were limited (Köhler et al., 2019). In this paper, I introduce a macroeconomic approach to MLP.

The proposed model exceeds existing evolutionary economic models by its macroeconomic coverage (cf. Köhler et al., 2018). It captures feedbacks across different groups of agents and markets that represent a whole macroeconomy including a financial system. Moreover, the model explicitly accounts for nonlinear complex dynamics with self-reinforcing feedback loops between technology supply and demand which are difficult to capture by existing macroeconomic approaches used to study energy transitions (see e.g. Köhler et al., 2018; Moallemi and de Haan, 2019, for reviews of existing modeling approaches). This study is aimed at advancing the theoretical understanding and modeling of large-scale 
transitions to improve the understanding of broader (macroeconomic) side effects.

Second, this paper also contributes to the literature on technological competition and learning feedbacks. The model builds on the theoretical framework of competing technologies in the presence of increasing returns (cf. Arthur, 1989; Cowan, 1991). It expands this framework to the macroeconomic level of analysis and allows a systematic distinction between technology types.

Third, the paper contributes methodologically and theoretically a new perspective to the macroeconomic literature on directed technological change. It allows distinguishing competing technologies systematically and aims to open the black box of long run substitutability. This is critical for the pace, costs and distributional consequences of directed technological change (cf. Acemoglu, 2002; Nijkamp et al., 2005; Lemoine, 2018). In the majority of existing studies, substitution elasticities are estimated or taken from the literature but a consistent microeconomic explanation based on observable properties of technologies and adopters is lacking. This paper proposes a microeconomic explanation of evolving substitution behavior and provides a consistent link to emerging macroeconomic patterns.

This paper is structured as follows. First, based on a literature review, empirical stylized facts of technology diffusion are elaborated. In Sec. 3, these insights are synthesized as characterization of competing technologies. The model is introduced in Sec. 4. In Sec. 5, simulation experiments are used to study the interplay between the characteristics of technology, policy and emerging transition pathways. Sec. 6 concludes.

\section{Diverse pathways of transition - empirical stylized facts}

Here, I introduce four stylized facts (SF) about the techno-economic dimension of transitions based on the empirical literature.

At the country-level, Dechezleprêtre et al. (2011) illustrated differences in the cross-country diffusion of green innovations measured by patent applications. Comin et al. (2006) have shown that historical technology diffusion rates differ across countries and technology types. They disproved the general validity of s-shaped diffusion patterns (cf. Allan et al., 2014) and explained cross-country heterogeneity by different stages of economic development. Adner and Kapoor (2016) have shown that the characteristics of both (the entrant and incumbent) and cross-technology interactions in the innovation process need to be considered to understand the heterogeneity of diffusion patterns.

The adoption of electric vehicles (EV) and renewable energy technologies (RET) is an example of country-level heterogeneity. The energy sector and automotive industry in India and China are rapid adopters of green technologies (Fu and Zhang, 2011; Lema and Lema, 2012; Jiang and Lu, 2018). Firms and the government are aware that it is more difficult to compete with Western market leaders in mature, highly specialized incumbent technologies (Jiang and Lu, 2018). Supported by national policy, Indian and Chinese car manufacturers began early to switch to EV (Lema and Lema, 2012; Tyfield and Zuev, 2018). 
Another example is RET in South Asia and Africa. The lacking availability and reliability of fossil fuel-based electricity systems are positively related to the diffusion of (decentralized) RET (Lema and Lema, 2012; Pfeiffer and Mulder, 2013). The low maturity of the incumbent is part of the explanation for the rapid take-off of entrant technologies.

In contrast, major developed countries struggle with path dependence. Accumulated infrastructure and technological knowledge is built upon a fossil fuel dominated technological paradigm (Unruh, 2000). Driven by effective policies, Germany became one of the technological leaders in the development solar PV and wind technologies (Quitzow, 2015; Pan et al., 2017) but a profound transition of the domestic energy sector is long in coming (Geels et al., 2016; Kemfert et al., 2018). The reasons are accumulated infrastructure but also cultural rules, societal resistance and inappropriate institutional frameworks to integrate RET into the market (Pahle, 2010; Nordensvärd and Urban, 2015; Geels et al., 2016; Herrmann and Savin, 2017).

A similar observation applies to the German automobile industry. The industry is highly innovative and globally competitive in the production of vehicles with internal combustion engines (ICE). This specialization is deeply entrenched in the domestic production network. The industry and the government failed to initiate the transition to low carbon technologies in time (Altenburg et al., 2015).

These observations indicate that a low-carbon transition is more challenging if firms accumulated high technological expertise in carbon-intensive incumbent technologies in relation to green alternatives. Accumulated knowledge and supporting infrastructure required for the effective use of the green entrant technology in relation to those required for the incumbent describe the relative maturity of the entrant (Geels and Schot, 2007).

These observations motivate SF1:

SF 1. The relative endowment with technology-specific knowledge and tangible assets ("relative maturity") influences individual adoption behavior.

This SF is also reflected in the history of EV and RET. During the formative phase, both were fair competitors. Cumulative learning, infrastructural, regulatory adjustments and the evolution of consumer habits and norms contributed to the emergence of a fossil fuel-based technological regime (e.g. Geels, 2005; Høyer, 2008; Jones and Bouamane, 2011, 2012). Spillovers within the technoinstitutional complex built upon fossil fuel energy contributed to the realized cost-effectiveness and reinforced path dependencies (Unruh, 2000). ${ }^{1}$

The relative endowment with technology-specific knowledge relates to the diffusing technology (and its suppliers) and the absorbing market. This is one

\footnotetext{
${ }^{1}$ Unruh (2000) and Grübler (1991) elaborate these spillovers further. Spillovers arise from overlaps in supply chains and networks, applications and endogenous innovation in complementary industries (e.g. in the petrochemical industry), institutional and political support and societal interest groups that contribute to the formation of norms and values and from education systems that shape the type of available skills at the labor market.
} 
explanation why diffusion patterns of the same technology may differ across industries and firms.

For the automobile sector, Aghion et al. (2016); Wells and Nieuwenhuis (2012) and Wesseling et al. (2015) have shown that the type of pre-existing specialization may influence firms' choice among different low-carbon technology options. Using input-output data, Carvalho and Voigtländer (2014) have shown that the adoption of production inputs is positively dependent on the technological similarity between the input producing sector and absorbing firms. Boehm et al. (2016); Acemoglu et al. (2016); Oikawa (2017); Huang et al. (2018) made similar observations. The similarity is positively related to knowledge spillovers across sectors and technology fields in learning processes (Jaffe and De Rassenfosse, 2017; Korzinov and Savin, 2018).

Adner and Kapoor (2016) studied interactions between the incumbent and entrant technology in the innovation process. They focused on the characteristics of an innovation, its interaction with pre-existing technology and the (co)evolution complementary factors. They showed that the pace of diffusion is retarded if an innovation is competence-destroying (Tushman and Anderson, 1986), if technological bottlenecks in the supportive innovation system arise or if external developments improve the realized performance of the incumbent. The authors emphasize the importance of dynamic interactions between competitors. This leads to SF2:

SF 2. Cross-technology interactions in the accumulation of supporting factors influence the pace of technological specialization reflected in the relative realized performance of competing technologies.

Many basic (green) technologies have their origins in the late 19th century. Examples are RET, EVs and organic food (Belz, 2004; Ma and Sauerborn, 2006; Høyer, 2008; Neukirch, 2009; Jones and Bouamane, 2011, 2012; Behera et al., 2012). ${ }^{2}$ Early deployment took place in niche markets characterized by very specific consumer preferences or governmental procurement. These niches provided a protected space that allowed these technologies to mature free from the pressure of price and performance competition with technologies that provide a similar output (e.g. electricity, propulsion technology, food in the examples above). External shocks (e.g. preference shifts, regulation, price shocks) allowed these innovations to challenge the dominant position of the incumbent. The interest to commercialize RET and EV at the mass market rose in the aftermath of the oil price shock in the 70s. The oil crisis coincided with an increasing awareness for the finiteness of resources and the environment, that became part of the political agenda. Prices, political support and regulation were key drivers of a new surge of entrepreneurial and innovative activities in RET and EV technology (Høyer, 2008; Popp et al., 2010; Geels et al., 2011; Jones and Bouamane, 2011, 2012; Geels et al., 2016; Popp, 2019). The dynamics in the organic food market

\footnotetext{
${ }^{2}$ Here, I refer to organic food as a product innovation that is explicitly labeled as distinct from conventional agriculture (cf. Reganold and Wachter, 2016).
} 
were to a larger extent driven by changing consumer preferences reflected in a higher willingness to pay, incremental regulation, support policies, labels and standardization (Belz, 2004; Ma and Sauerborn, 2006; Lockeretz, 2007; Behera et al., 2012; Reganold and Wachter, 2016).

Other technologies gained momentum through a technological breakthrough even though it took time until the incumbent was replaced (cf. Geels and Schot, 2007; Malerba et al., 1999). These observations lead to SF3:

SF 3. External shocks may trigger the market entry of a technology that competes to replace the incumbent solution.

Transitions can be accompanied by changes in the market structure and the redistribution of income and wealth. These effects are observable at the labor market, across firms within the same industry and across industries. Whether and to which extent these side effects occur is dependent on the capacity of employees, firms and industries to cope with new technology.

Vona et al. (2015) and Consoli et al. (2016) empirically documented that the adoption of green technologies can be associated with structural change in the labor market. Occupations and skills needed for the operation of green technologies differ from those demanded for the incumbent. Skill-biased technological change may be associated with a redistribution of income when relative wages for skills required for the entrant technology increase at the expense of the incumbent (e.g. Acemoglu, 2002; Autor et al., 2003). Vona et al. (2015) did also find that the pre-existing skill-profile of industries determines the pace and ease at which industries adopt green technologies in response to environmental regulations. Industries that are characterized by a high share of employees with "green skills" adopt green technologies more effectively.

Tushman and Anderson (1986) have shown that the compatibility of preexisting knowledge with the utilization of new technologies can explain changes in the market structure. Competence destroying innovations, that require radically different knowledge, tend to be introduced by entrant and not by incumbent firms. This leads to a reallocation of market shares within the same product group. Wesseling et al. (2015) adopted the framework of competence-destroying innovations and investigated the responses of automobile firms to technology-forcing regulation. They illustrated that firms' with the least compatible competences exhibited the most opposing behavior and missed the entry to the low-emission vehicle market.

Breschi et al. (2000) linked the properties of technological learning processes to emerging Schumpeterian patterns of innovation, i.e. whether innovative activity deepens pre-existing hierarchies among incumbent firms (creative accumulation) or whether it is associated with a widening allowing market entering firms to become technological leaders (creative destruction). If new technologies are compatible with firms' existing competences, firm hierarchies tend to be stable and innovative activities are concentrated among the incumbents. In contrast, if new technologies require different types of knowledge and if the pre-requisites to acquire the relevant knowledge are low, the market is characterized volatile entry-exit dynamics. 
Changes in the market structure and transition costs can be used to describe the degree of disruption of a transition process. Disruption is low if incumbent dominant firms (regime actors) successfully adapt at low costs to new circumstances and preserve their dominant position in the market. Transition costs are low when pre-existing knowledge can be transfered to the use of the new technology. The degree of disruption is high if transition costs are high and/ or the hierarchies of dominant actors are changed.

These observations lead to SF4:

SF 4. The degree of disruption of a transition depends on regime actors' capacity to cope with the new technology.

Note that these SFs and all concepts introduced in this paper refer to the dimensions of transitions that are measurable by economic indicators such as diffusion rates, market concentration, entry-exit dynamics, progress rates and measures for the technological relatedness.

\section{MLP and a dynamic characterization of competing technologies}

\subsection{Pathways of transition - theory}

A common theoretical framework to study technology transitions is the multilevel perspective (MLP) (Smith et al., 2010; Lachman, 2013; Köhler et al., 2019). In MLP, socio-technical systems are decomposed into three interacting levels, called landscape, regime and niche.

The regime describes a dominant technical solution to fulfill a societal function (Kemp, 1994; Geels, 2002; Geels and Schot, 2007). It is associated with a technological paradigm that determines how technology users and developers define technological problems and search for solutions (Nelson and Winter, 1977; Dosi, 1982). A regime is stabilized dynamically by incremental technical improvements, the accumulation of experience, the built-up of supporting infrastructure, regulation and the deepening societal and economic entrenchment ("endogenous renewal").

The landscape-level reflects external conditions into which a technological regime is embedded. Internal problems of the regime or changes in the landscape may put the regime under pressure. This creates windows of opportunity for emerging niche technologies to replace the existing regime. Transitions from niche to the regime are driven by the enactment of different societal groups and interactions among different levels (Geels, 2002).

MLP provides a framework for the systematic, empirical and theoretical study of technology transitions. It was used to study historical and current transitions in different technology fields and countries (e.g. Kemp, 1994; Geels, 2002; Geels et al., 2011; Safarzyńska et al., 2012; Yuan et al., 2012; Wells and Nieuwenhuis, 2012; Berkeley et al., 2017; Köhler et al., 2019; Geels et al., 2016).

Geels and Schot (2007) proposed a typology to distinguish different transition pathways. Their typology is dependent on the timing and nature of multi-level interaction. The timing refers to the timely coincidence of sufficiently mature 
niche technologies and landscape pressure. The nature of interaction describes the ability of regime actors to cope with emerging niche technologies and to adapt to landscape pressure. Regime actors are e.g. firms, consumers and interest groups who have vested interests in preserving the incumbent technology. The authors show how the timing and nature of multi-level interactions may be associated with different transition pathways.

Different pathways have implications for the power relations and degree of disruption of technological change. In this paper, I subsume the behavior of societal groups and actors to the adoption behavior of firms. In contrast to the majority of existing transition modeling studies based on MLP (cf. Köhler et al., 2018; Moallemi and de Haan, 2019), this is a purely economic approach.

The technological regime is defined by the type of production technology that is used by firms. Firms are regime actors. A transition is disruptive if the hierarchies among firms change throughout the process of technological change, i.e. if those firms that are dominant under the incumbent technological regime lose market share to entrants or exit the market. It is also disruptive when the switch from the incumbent to the entrant technology is costly. The degree of disruption is low if firms that are successful under the incumbent regime can adopt the new technology at low costs and/ or preserve their market position.

Firms are neutral regarding the type of technology but have endogenously accumulated vested interests that are embodied in physical capital and intangible knowledge. The technology choice is conditional on the relative, realized performance of a technology given existing stocks of tangible and intangible assets and the market environment provided by the landscape.

\subsection{A characterization of competing technologies}

Competing technologies can be described by three groups of properties that have different implications for the evolutionary transition dynamics.

Stock variables are cumulative technology-specific knowledge and supporting factors. Stock variables can be used to describe the maturity of technologies used at the niche and regime level. Agents (e.g. firms, consumers, interest groups) accumulate stock-variables by intended research and investment and, unintendedly, as a byproduct of learning by using. Accumulating stocks stabilize the regime (Geels, 2002).

The ratio of technology-specific stocks accumulated by the agents describes the relative maturity of the entrant compared to the incumbent. This ratio is a measure for the timing of regime-niche interaction (Geels and Schot, 2007). The relative maturity has an impact on the adoption behavior of individual agents active at the niche and regime level (SF1).

For example, the stabilization of ICE-based automobility as dominant technology for passenger transportation arose from the accumulation of supporting factors (e.g. regulatory adjustments, complementary infrastructure, performance improvements, skills of manufacturers) (Geels, 2005). Alternative transportation technologies that might possibly replace ICE 
mobility have to compete with these evolving stocks of technological knowledge. After the oil price shock in the 70s, the low initial technical maturity, lack of supporting infrastructure and adaptive innovations of ICEs (fuel efficiency, exhaust filters) dampened optimism in emerging EV projects (Høyer, 2008; Geels et al., 2011; Wells and Nieuwenhuis, 2012).

Interactive properties influence the relative pace of accumulation of stock variables (pace of specialization). This is reflected in the relative realized performance of competing technologies (SF2). Technological trajectories diverge if the relative maturity diverges. This occurs if the accumulation process in one technology is faster compared to the other. Interactive properties describe how easily agents can switch from the regime to niche technology and vice versa. Path dependence is weaker if it is easier for agents to switch.

Interactive properties can be operationalized as technological similarity and difficulty. The similarity has implications for the cross-technology transferability of accumulated stocks. The technological difficulty (or complexity) describes how easily stock variable can be accumulated (Cohen and Levinthal, 1990; Lema and Lema, 2012). A higher difficulty is associated with higher returns to specialization. Both properties affect the capacity of agents (firms) in the incumbent regime to adapt to an emergent niche technology (cf. Tushman and Anderson, 1986; Geels and Schot, 2007).

For example, the production of both electric and ICE vehicles is technically very difficult. It requires a high level of technology-specific capabilities and a large number of technology-specific intermediate inputs. Both technologies are also very dissimilar. For example, the production of batteries for EV and combustion engines requires different technological skills and different material inputs (Høyer, 2008; Wells and Nieuwenhuis, 2012). This makes it difficult for companies to specialize in both technologies simultaneously. Empirically, it was observed that technological leaders in the ICE sector struggle with the adoption of EV technology and explored (with limited success) fuel cells or biofuels as climate-friendly alternatives that are more compatible with the pre-existing ICE specialization. Early adopters of $\mathrm{EV}$ technologies are either market entrants or do not operate at the performance frontier of ICE technology (Ehret and Dignum, 2012; Wells and Nieuwenhuis, 2012; Altenburg et al., 2015; Wesseling et al., 2015; Berkeley et al., 2017).

Exogenous properties are landscape conditions that surround the evolution of technological competition between the regime and the emergent niche. These conditions determine the economic valuation of specific properties of a technology. Exogenous shocks in the landscape conditions can trigger the market entry of a new technology (SF3). Exogenous properties have an impact on the market performance of niche and regime technologies.

For example, a fuel-saving technology is not valuable if fuel is for free. Organic food is not superior in the market if consumers do not have a 
specific preference or if production is unregulated. These conditions are beyond the control of individual agents and follow dynamics that are independent of technology race. They are considered as given in daily decision making of technology users and developers (Geels, 2002).

These concepts are embodied in the Eurace@unibi-eco model. It will be shown that the model offers a link between the characteristics of competing technologies to emergent transition pathways and their degree of disruption (SF4).

\section{A macroeconomic ABM of technology transitions}

Here, I give only a concise conceptual introduction to the model. A comprehensive formal documentation is available in Hötte (2019b).

\subsection{The model}

The model is an extended version of the macroeconomic ABM Eurace@unibi (Dawid et al., 2019a). The extended model is illustrated in Fig. 1. It can be used to simulate a whole macroeconomy covering markets for consumption and capital goods, labor, credit and finance. Agents interact on these markets and exchange goods, labor and information.

[Fig. 1 about here.]

Heterogeneous firms produce a final consumption good that is offered on the goods market. Households supply labor to firms. Their wage income is spent for consumption and saving or invested in risky assets. Capital producers offer capital goods to firms and invest in R\&D to increase the productivity of supplied capital. The model is financially stock-flow consistent, i.e. financial flows between agents are mutually settled. Private banks manage households' and firms' deposits and give credit to firms if firms' financial means are insufficient to finance current expenditures and investment. Agents' routines are executed stepwise. One iteration corresponds to one working day. Some routines are executed on a regular frequency, e.g. daily or monthly, others are event-based. For example, firms only demand credit if their financial means are insufficient.

The model is empirically validated, i.e. it is able to reproduce a number of micro- and macroeconomic empirical stylized facts. ${ }^{3}$ In previous studies, the baseline model had been used to study economic policies (e.g. Dawid and Gemkow, 2013; van der Hoog and Dawid, 2017; Dawid et al., 2018, 2019a,b; Harting, 2019). The model extension was used to study technology diffusion barriers and learning spillovers (Hötte, 2020, 2019d).

In this study, the most relevant agents are firms, capital producers and households. Firms produce final goods using capital $K$ and labor $L$ as inputs.

\footnotetext{
${ }^{3}$ The model reproduces auto- and cross-correlation patterns of e.g. price-sets, mark-ups, unemployment, output, Phillips and Beveridge curves, aggregate growth rates and business cycle volatility patterns.
} 
Capital is heterogeneous by technology type $\tau$ and supplied by two competing capital producers $\tau=c, g$. Producer $c$ is incumbent in the market and offers conventional capital goods that require costly natural resource inputs in use. The other producer $g$ is a green entrant that offers a resource-saving alternative.

Final goods fulfill a societal function and can be equally well produced by the use of $c$ or $g$. The incumbent technology type $c$ dominates firms' production technology. It represents the technological regime. The entrant technology $g$ is an emergent niche that is possibly adopted by firms. In this model, the role of agency is reduced to the role of firms that can (gradually) switch between the regime and niche technology through capital investments.

Firms behavior follows an economic rationale. It is goal-oriented, but constrained by imperfect foresight and limited information-processing capacity. Routines simplify firms' decision-making in complex, uncertain and dynamically changing environments (Simon, 1957; Nelson and Winter, 1982). Firms are active on a competitive market that can be affected by landscape shocks. For example, resource scarcity or stringent policy might affect the price of the resource input required to operate the regime technology.

[Table 1 about here.]

Firms, indexed by $i$, invest in capital that is accumulated as stock. Firms' capital stock is composed of a range of (possibly) different capital goods. It depreciates over time and is maintained or expanded through investment. Single capital goods ("vintages" $v$ ) differ by technology type $\tau$ and productivity level $A^{v}$. Each capital producer offers a range of vintages differing by $A^{v}$. If the producer in sector $\tau$ successfully innovates in time $t$, it brings a new and more productive vintage to the market. The sectoral productivity frontier $A_{\tau, t}^{V}$ is shifted upwards. The probability of innovation success depends on R\&D expenditures. Capital producers invest a fraction of profits in $\mathrm{R} \& \mathrm{D}$. This is a source of increasing returns in sectoral innovation. The capital producer with better market performance innovates relatively faster. Capital producers set prices according to an adaptive pricing rule. This reflects the market response and scarcity in capital supply. It partly counterbalances increasing returns.

Labor $L_{i, t}$ is required by firm $i$ to operate capital. It is hired at the labor market. Heterogeneous employees $l \in L_{i, t}$ are endowed with technology-specific skills $b_{l, t}^{\tau}$. These skills are needed to exploit the productivity of capital. Employees need to know how to work with green or conventional machinery. They learn technology-specific know-how when working with capital type $\tau$ ("learning by doing “, LBD). If employees of a given firm work more intensively with green (conventional) capital, they accumulate green (conventional) skills relatively faster.

Technology-specific skills $B_{i, t}^{\tau}=\frac{1}{L_{i, t}} \sum_{l \in L_{i, t}} b_{l, t}^{\tau}$ aggregated across the whole workforce $L_{i, t}$ determine the $i$ 's effective technology-specific productivity. Skills are a source of evolving, heterogeneity of firms' technology-specific adoption benefits. When investing in new capital, firms estimate and compare the net present value (NPV) of different options. They decide about the quantity, 
technology type $\tau$ and productivity level $A^{v}$. They form expectations about future prices, wages, demand and the evolution of employees' skills.

The process of LBD depends on the interactive properties of competing technologies. The technological distance $\chi^{\text {dist }} \in[0,1]$ is an inverse measure for the cross-technology knowledge transferability. If the distance is small, technologies are similar. Acquired skills that are useful to operate conventional technology are also useful for the operation of green capital and vice versa.

The second interactive property is the technological difficulty $\chi^{\text {int }} \in \mathbb{R}$. It describes the effectiveness of relative effort $\nu_{i, t}^{\tau}$ in LBD. $\nu_{i, t}^{\tau}=K_{i, t}^{\tau} / K_{i, t}$ is the share of capital $K_{i, t}^{\tau}$ of type $\tau$ that is used in firm $i$ in $t$ with $K_{i, t}=K_{i, t}^{c}+K_{i, t}^{g}$. It measures the relative time of working with $\tau$. $\chi^{\text {int }}$ is a measure for the returns to technological specialization. If $\chi^{\text {int }} \rightarrow 0$, both technologies are very easy to learn, i.e. LBD is independent of $\nu_{i, t}^{\tau}$. This may reduce the costs of transition because two technology types can be used simultaneously. If $\chi^{\text {int }}$ is high, the technology is difficult to learn and LBD is inefficient if both technologies are used at the same time. If $\chi^{\text {int }}>1$, returns to specialization are increasing in $\nu_{i, t}^{\tau}$. More detail is available in Appendix A.

Macroeconomically, the technological evolution is driven by two learning processes. The productivity of supplied capital $A_{\tau, t}^{V}$ is interpreted as codified knowledge. Its evolution is driven by a process of intended "learning by (re)searching " reflected in R\&D investments. Technology-specific skills of employees $B_{i, t}^{\tau}$ are interpreted as tacit knowledge (cf. Cowan et al., 2000). In contrast to codified, tacit knowledge is not explicitly traded on the market and needs to be learned at the firm. ${ }^{4}$

Both learning processes are subject to increasing returns dependent on the technological state of the economy. The state at the macroeconomic level is evaluated by the share of conventional capital $\nu_{t}^{c}$ that is used in current aggregate production. If $\nu_{t}^{c} \rightarrow 0$, a transition to green technology has occurred. environment

\subsection{The characteristics of competing technologies in Eurace@unibi-eco}

The characteristics of competing technologies are operationalized as follows:

Stock variables are embodied in the accumulated codified knowledge (productivity) $A_{\tau, t}^{V}$ of capital producers and tacit knowledge $B_{i, t}^{\tau}$ of firms. Both stocks affect the realized performance and have an impact on green technology adoption behavior of individual firms (SF1).

The ratio between the technology-specific stock variables $\alpha_{t}=\frac{A_{g, t}^{V}}{A_{c, t}^{V}}$ and $\beta_{t}=\frac{B_{t}^{g}}{B_{t}^{c}}$ determines the relative maturity of the entrant. Increasing divergence in the relative endowment with technology-specific stocks drives the process of convergence to the final regime.

\footnotetext{
${ }^{4}$ Tacit knowledge has a similar effect as supportive infrastructure, routines and habits. It is a supporting factor that facilitates effective technology use.
} 
Interactive properties describe interactions in the accumulation of knowledge. This is leads to the divergence of relative stocks. Interactive variables are given by the spillover intensity $\chi^{\text {dist }}$ and returns to specialization $\chi^{\text {int }}$ in LBD. Both affect the pace of specialization reflected in the effective productivity of a technology type (SF2).

Exogenous properties are landscape conditions that influence the valuation of inputs and outputs. These properties are reflected in the price for the natural resource input, in relative production costs of capital goods and consumer preferences that determine the relative willingness to pay for final goods produced with a specific technology type. These properties determine the relative superiority of the green technology in the landscape.

In a baseline simulation, landscape pressure on the incumbent comes from the costs of resource inputs. A breakthrough enables the production of green capital that allows adopters to save input costs. The price for the resource is sufficiently high that the green technology can challenge the incumbent (cf. SF3). In a policy experiment in Sec. 5.3, I show how market-based policies may influence the type and strength of landscape pressure.

\section{Simulations and experiments}

The model is used to simulate a competitive race between two technologies. The simulations are run over a time horizon of $T=15,000$ iterations that correspond to roughly 60 years.

\subsection{Baseline and calibration}

At the beginning of the simulations, the conventional technology dominates the market and is entrenched in the production system. The capital stock of firms consists only of conventional capital. Firms and employees have accumulated the matching skill type $b_{l, t}^{c}$ needed to operate these machines. The conventional capital producer invests a fraction of profits to improve the productivity of supplied capital incrementally. Learning and innovation dynamics are "aligned", i.e. both are directed to the improvement of conventional capital. This stabilizes the regime. Permanent pressure from the landscape is reflected in the price of the resource required to operate conventional capital. But a sufficiently mature alternative technology to challenge the regime is lacking. ${ }^{5}$

Enabled by a technological breakthrough, the green capital producer enters the market in $t=600$ (after 2.5 years). The green technology is technically superior because it allows firms to get rid of the costly resource inputs. ${ }^{6}$ But

\footnotetext{
${ }^{5}$ In the simulations, the price for the resource input is set to $10 \%$ of real labor costs. Over time, this cost-share is held constant, i.e. the price evolves proportionally to average wages.

${ }^{6}$ Alternative interpretations are the costs of environmental regulations or other inputs that are relatively more costly than those required to operate the entrant technology.
} 
it suffers from lower maturity. This is operationalized by lower endowments of accumulated knowledge. Employees have not yet worked with green capital and the technical maturity of supplied capital is lower. Lower initial maturity, reflected in employees skills and the productivity of capital, is a barrier to diffusion (cf. Arundel and Kemp, 2009; Triguero et al., 2013).

Diffusion barriers are implemented as a factor $\beta^{A}\left(\beta^{b}\right)$ that scales down the initial productivity (skill level) of the entrant, i.e. $A_{g, t_{0}}^{V}=\left(1-\beta^{A}\right) A_{c, t_{0}}^{V}$ and $b_{h, t_{0}}^{g}=\left(1-\beta^{b}\right) b_{h, t_{0}}^{c}$ with $\beta^{A}, \beta^{b} \in[0,1)$.

The dynamics of competition depend on the ratio between technical superiority (resource cost savings) and the technological disadvantage (lower maturity). The green technology has the chance to diffuse if it is sufficiently superior given its relative maturity. Otherwise, the regime can preserve itself. Monte-Carlo (MC) simulations serve as benchmark for a policy experiment, i.e. diffusion barriers $\left(\beta^{A}, \beta^{b}\right)$ and learning parameters $\left(\chi^{\text {dist }}, \chi^{\text {int }}\right)$ are drawn independently at random from predetermined interavals summarized in Table 2 . The intervals had been identified in an iterative procedure. They are determined such that trivial patterns of monotone diffusion or lock-in are avoided and a well-mixed sample of transition and lock-in regimes is obtained. This offers a large variety of transition pathways that are statistically analyzed. The model complexity and non-linearities prevent the analytical derivation of parameters. ${ }^{7}$ In the benchmark simulations, the green technology "wins" in about $30 \%$ of runs.

[Table 2 about here.]

The outcome of the technology race depends on competitive dynamics and stochastic elements in microlevel functions. For example, innovative success is probabilistic and may shift the relative productivity critically in favor of one technology. Also households' purchasing behavior and matching processes on the labor market have stochastic elements. This may critically affect the performance and investment behavior of firms. These small events may tip the technological evolution into one direction that is stabilized by increasing returns.

The technological dimension of the model is designed along a series of stylized facts documented in the innovation literature. The simulations are not aimed at reproducing technological trajectories of any specific example of green or brown technology. Instead, it is a theoretical model aimed at identifying sources of heterogeneity in transition pathways and the qualitative link between transitions and potential macroeconomic consequences. The design and validation criteria of the model are summarized in Table 3 .

[Table 3 about here.]

The model is used to generate a sample of simulated transition curves as illustrated in Fig. 2a where each line represents a single run. The transition process is measured by evolution of share of conventional capital $\nu_{t}^{c}=K_{t}^{c} / K_{t}$. Single

\footnotetext{
${ }^{7}$ More information is available in Appendix B and a comprehensive working paper (Hötte, 2019c). Code and data are available to ensure transparency and reproducibility (Hötte, 2019a).
} 
curves exhibit very diverse patterns. In some cases, the economy is locked in and the green technology does not diffuse at all, i.e. $\nu_{T}^{c} \rightarrow 1$. In other cases, the green technology is quickly taken up and the green regime stabilizes at $\nu_{T}^{c} \rightarrow 0$. The process can be very unstable. This occurs if the green technology is taken up initially, but path dependence in the accumulation process of knowledge is high. Initial diffusion is reversed. Sometimes, a change in the direction of the process occurs multiple times and the economy switches between lock-in and green transition.

[Fig. 2 about here.]

The standard deviation $\sigma_{t}^{\nu}$ of $\nu_{t}^{c}$ is a measure to operationalize the stability of the transition. It is illustrated in Fig. 2b. The switching behavior is costly because learning and $R \& D$ resources are wasted for a technology type that is obsolete in the long run. ${ }^{8}$

\subsection{Market-based diffusion policies}

Political instruments can be used to accelerate a transition. In an experiment, I evaluate three policies that alter the market conditions. These instruments are (1) a resource tax that penalizes the use of conventional capital, (2) an investment subsidy that makes investments in green capital cheaper and (3) a price support for green products that stimulates the creation of green product markets.

The policies are operationalized as follows:

1. The $\operatorname{tax} \theta$ is imposed on the resource input price $p_{t}^{\text {eco }}$, i.e. $\tilde{p}_{t}^{\text {eco }}=(1+\theta) \cdot p_{t}^{\text {eco }}$.

2. The investment subsidy $\varsigma^{i n v}$ reduces the price of green capital goods $p_{t}^{g}$, i.e. $\tilde{p}_{t}^{g}=\left(1-\varsigma^{i n v}\right) \cdot p_{t}^{g}$.

3. $\varsigma^{\text {cons }}$ is a price support that reduces consumer prices $p_{i, t}$ for products produced with green capital. The level of support is proportional to the share of green capital $\nu_{i, t}^{g}$ at firm $i$, i.e. $\tilde{p}_{i, t}=p_{i, t} \cdot\left(1-\left(\nu_{i, t}^{g} \cdot \varsigma^{\text {cons }}\right)\right)$. Firms with a higher $\nu_{i, t}^{g}$ receive a relatively higher subsidy on sales.

The budget of the government is balanced in the long run. Net expenditures of policies are settled by adaptive income and corporate taxes. Taxes are increased (decreased) if smoothed net financial inflows of the government are negative (positive).

More generally, these instruments reflect landscape conditions when ignoring the budgetary implications. The tax is analog to the price for the natural

\footnotetext{
${ }^{8}$ The coefficient of correlation between annual output growth and $\sigma_{t}^{\nu}$ is $-4.466 \%$. An OLS regression with two-way clustered standard errors confirms the significance, i.e.

$$
\% \text { growth }_{t}=1.89^{* * *}-.0085 \cdot \sigma_{t}^{\nu * * *}+\epsilon_{t} .
$$

Technical detail is available in II. Some general description of these baseline simulations is provided in I.2.
} 
resource. The investment subsidy reflects the availability of resources required for the production and installation of green capital goods. The consumption subsidy is analog to a shift in consumer attitudes reflected in a higher willingness to pay for green products.

In the following, I describe first the impact of different policies on the technological evolution and discuss interactions between the instruments and the characteristics of technologies. Thereafter, I illustrate the policy effects on macroeconomic indicators within the Eurace@unibi-eco economy.

\subsection{Technological learning and the effectiveness of diffusion policy}

To analyze the effectiveness of policies, another Monte-Carlo experiment with 210 simulations à 15,000 iterations is run. The levels of diffusion barriers, learning parameters and policy rates are drawn independently at random from uniform distributions of predetermined intervals (see discussion above). All three instruments are used simultaneously. The impact of single instruments and its dependence on initial conditions can be statistically isolated. The initialization is summarized in Table 6 in Appendix B.

The outcome of the policy experiment is compared descriptively to the benchmark with the same average levels of initial maturity and learning parameters.

\subsubsection{The impact on the technological evolution}

A descriptive comparison suggests that policies stimulate a transition. In the benchmark scenario, the economy converges to a green technological regime in $30 \%$ of all runs. This is much lower compared to the policy experiment with a transition frequency of $70 \%$. This is reflected in Fig. 3a showing $\nu_{t}^{c}$ as aggregate across runs. ${ }^{9}$ The black (gray) line indicates the experiment (benchmark).

[Fig. 3 about here.]

Fig. 3b shows the diffusion curve disaggregated by regime (green transition or lock-in). In the lock-in regimes, green technology take-up is higher until the reversal to conventional technology occurs. This suggests that the policies accelerate diffusion independently of the emerging regime. The higher uptake of green technology is reflected in a higher volatility $\sigma_{t}^{\nu}$ in the beginning. It jumps up early after the market entry and approaches zero when the economy converges to one of the two technological regimes (cf. Fig. 3c).

The impact of the policies on the transition probability can be presented as a shift in the transition boundary. The probability is dependent on the initial maturity of the entrant. The transition boundary is a dividing line in the two-dimensional space of initial relative knowledge stocks $\alpha_{t_{0}}$ and $\beta_{t_{0}}$. Higher levels of $\alpha_{t_{0}}$ and $\beta_{t_{0}}$ indicate less favorable starting conditions for the entrant,

\footnotetext{
${ }^{9} \mathrm{An}$ aggregate value of 0.30 means that, on average, $30 \%$ of capital goods that are used for production at time $t$ are conventional and the remaining $70 \%$ are green. Due to the convergence to a value of 0 or $1, \nu_{T}^{g}=1-\nu_{T}^{c}$ measured at the end of simulations $T$ and aggregated across runs approximates the transition probability.
} 
i.e. a lower relative maturity in $t_{0}$. Fig. $4 \mathrm{a}(4 \mathrm{~b})$ shows the transition boundary in the benchmark (policy) scenario. An upward shift of the transition boundary is observed. Hence, policies may effectively compensate for initial technological disadvantages.

[Fig. 4 about here.]

Regression analyses reveal structural relationships between different policies, the characteristics of technologies and their impact on the transition probability and pathway. The transition probability is approximated by the diffusion measure $\nu_{i, T}^{c}$ at the firm level in $T=15,000$. Until $T, \nu_{i, t}^{c}$ has converged to one (zero) if the economy is locked in (a transition occurred). ${ }^{10}$ The shape of the transition pathway is described by a set of different indicators. The time until stabilization $t_{i}^{*}$ measures the period when the last switch between different technology types was observed. After $t_{i}^{*}$, the adoption behavior becomes monotone and firm $i$ invests in only one technology type.

Long-lasting switching behavior between technologies is associated with higher diffusion volatility. The volatility is measured by the variance $\left(\sigma_{i}^{\nu}\right)^{2}$ of $\nu_{i, t}^{c}$ computed across the whole simulation horizon. ${ }^{11}$ The degree of technological divergence is described by relative knowledge stocks $\alpha_{i}^{*}=\left(\frac{A_{i}^{+}}{A_{i}^{-}}\right)^{*}, \beta_{i}^{*}=\left(\frac{B_{i}^{+}}{B_{i}^{-}}\right)^{*}$ in $t_{i}^{*}$. The superscript $+(-)$ indicates the technology type that wins (loses) the technology race. A high $\alpha_{i}^{*}$ and $\beta_{i}^{*}$ indicate a high degree of divergence in $t_{i}^{*}$.

These indicators are used as dependent variables and regressed on policies $(\theta$, $\left.\varsigma^{i n v}, \varsigma^{\text {cons }}\right)$, initial barriers $\left(\beta^{A}, \beta^{b}\right)$, learning conditions $\left(\chi^{\text {int }}, \chi^{\text {dist }}\right)$, interaction terms of these parameters and a set of micro- and macroeconomic controls. A binary Probit regression is used to explain the transition probability. The other regressions are OLS.

The shape of the pathway and its interaction with explanatory variables may exhibit systematic differences across regimes. These differences are captured by the inclusion of interaction terms with a regime-dummy $\mathbb{1}$ (eco) that equals one if the emerging regime is green. An extract of the regression results is shown in Table $4 .{ }^{12}$ Explanatory variables are scaled by their standard deviation and demeaned to make the coefficients comparable.

[Table 4 about here.]

Column (1) and (2) represent the results of the transition probability. Column (3) illustrates the effect on the duration until stabilization. Column (4) and (5)

\footnotetext{
${ }^{10}$ The variation of $\nu_{i, T}^{c}$ across firms in $T$ is negligibly small. Its average (across runs) standard deviation accounts for .0064.

${ }^{11}$ The variance is computed firm-wise across the full time horizon, i.e. $\left(\sigma_{i}^{\nu}\right)^{2}=\frac{1}{T} \sum_{t=0}^{T}\left(\nu_{i, t}^{c}-\right.$ $\left.\bar{\nu}_{i}^{c}\right)^{2}$ with $\bar{\nu}_{i}^{c}=\frac{1}{T} \sum_{t=0}^{T} \nu_{i, t}^{c}$.

${ }^{12}$ To take account of possible endogeneity, the dummies are included through an instrumental variable regression. Technical details about the data processing, model selection, robustness checks and alternative specifications are provided in II. Here, I discuss only effects that are significant at $\mathrm{a}<.1 \%$ level if not explicitly mentioned differently.
} 
describe the technological divergence. The last column (6) shows the relation of policies with the diffusion volatility.

The core qualitative observations are the following:

All policy instruments are effective and are associated with a higher transition probability. The effect on the diffusion volatility and on the time until stabilization $t^{*}$ differs across instruments.

The effectiveness of the consumption subsidy $\varsigma^{\text {cons }}$ as transition stimulus is undermined by the distance and increasing returns to specialization (row (11)-(12)). Its effect can be even reversed if $\chi^{d i s t}$ and/ or $\chi^{\text {int }}$ are large. In contrast, the effectiveness of the $\operatorname{tax} \theta$ is reinforced by $\chi^{\text {dist }}$ and weakened by $\chi^{i n t}$. The investment subsidy $\varsigma^{i n v}$ is least sensitive to cross-technology interactions in LBD.

The distance $\chi^{\text {dist }}$ increases the diffusion volatility $\left(\sigma_{i}^{\nu}\right)^{2}$ and the duration until stabilization $t_{i}^{*}$ if a transition occurs, i.e. if $\mathbb{1}(e c o)=1$. If the economy is locked in, it has the opposite effect and stabilizes the technological evolution because it reinforces the specialization in conventional technology (cf. row (2) and (17)).

The duration until stabilization $t_{i}^{*}$ is differently affected by different policies and the effect differs across regimes. If the economy is locked in, $t_{i}^{*}$ is increasing in $\theta$ but decreasing in the level of subsidies (row (4)-(6)). The opposite is true if a transition is successful. Taxes accelerate (subsidies postpone) $t_{i}^{*}$ (row (18)-(20)).

The diffusion volatility $\left(\sigma_{i, T}^{\nu}\right)^{2}$ is negatively associated with $\theta$ and $\varsigma^{i n v}$ if a transition occurs, i.e. $\mathbb{1}(e c o)=1$. Both instruments stabilize a successful diffusion process but increase uncertainty if the economy is locked in. $\varsigma^{\text {cons }}$ has no significant effect in the transition regime and a negative one in the lock-in case. $\varsigma^{\text {cons }}$ is paid proportionally to the share of green capital use. Hence, the strength of support is dependent on $\nu_{i, t}^{g}$. The support stabilizes an ongoing diffusion process but diminishes if green technology is not used. In contrast, the strength of support of $\varsigma^{i n v}$ is independent of the technological state.

The strength of the relationship between the volatility and policies is conditional on the technological distance. The interaction of $\chi^{\text {dist }}$ with all policy instruments increases the volatility. The policies and $\chi^{\text {dist }}$ operate in opposite directions. Policies favor green technology uptake. Lacking learning spillovers reinforce path dependence. This operates in favor of the incumbent.

The technological divergence and the volatility tend to be negatively correlated. Explanatory variables that lead to a stronger divergence, i.e. higher $\left(A_{i}^{+} / A_{i}^{-}\right)^{*}$ and $\left(B_{i}^{+} / B_{i}^{-}\right)^{*}$, tend to be associated with lower volatility. This qualifies relative knowledge as driver of stabilization. 
Diffusion barriers may inhibit diffusion, but their effect is dependent on learning spillovers. The negative effect of the technical barrier $\beta^{A}$ is decreasing in $\chi^{\text {dist }}$. If the competing technologies are sufficiently dissimilar, productivity performance becomes relatively less important for diffusion compared to other factors.

In contrast, the inhibiting effect of $\beta^{b}$ is stronger if $\chi^{\text {dist }}$ is large. Lacking spillovers in LBD make it more challenging to reduce the skill gap. If $\chi^{\text {dist }}$ is high, firms are challenged by the incompatibility of pre-existing know-how when adopting green technology. External factors that are not related to productivity, e.g. variable input costs, become more important. This is also visible in the increasing effectiveness of the tax reflected in the negative coefficient of $\chi^{\text {dist }} \cdot \theta$ in the regression of $\nu_{i, T}^{c}{ }^{13}$

The different policies operate through different channels. The tax and the investment subsidy have an instantaneous effect on the relative cost-effectiveness of a technology. The tax compensates permanently for the technical disadvantage if adopting less productive technology. It operates through the channel of relative utilization costs. A less productive capital good that is bought remains in the capital stock until it is depreciated or taken out of use. The tax compensates for this disadvantage over the full life time of a green capital good. The permanent compensation may explain why the tax is associated with a lower time until stabilization if $\mathbb{1}(e c o)=1$.

The investment subsidy $\varsigma^{i n v}$ is neutral with regard to the relative technological performance over time and does not alter the conditions of market competition among firms using green or brown technology. It has an instantaneous effect on relative investment costs. Relative investment costs per productivity unit are sensitive to the dynamics of innovation success and price competition on the capital market (cf. Appendix A). This may explain why $\varsigma^{i n v}$ is associated with lower diffusion stability.

Differently than other instruments, the effectiveness of $\varsigma^{\text {cons }}$ is sensitive to the technological state. The strength of support is proportional to $\nu_{i, t}^{c}$. In the beginning, when firms adopt green capital but have a high share of pre-existing conventional capital, the level of subsidy support is relatively weak. The adoption decision is mainly influenced by the relative endowment with technological knowhow and the relative performance of the technologies. $\varsigma^{\text {cons }}$ reinforces ongoing transition but diminishes if the green technology is not used. It is asymmetric across firms depending on the type of technology that is used by firms.

\subsubsection{Macroeconomic side-effects}

Macroeconomic side effects of policies differ across instruments. The policies reinforce initial green technology uptake independently of the emerging regime.

\footnotetext{
${ }^{13}$ Keep in mind that this finding might be specific to the assumptions in the model. $\chi^{\text {dist }}$ is related to learning spillovers on the technology demand side. Spillovers in the innovation process might have an analogous effect.
} 
This is associated with macroeconomic side effects in both regimes. To reduce the scope of analysis, I consider only successful transitions. I focus on the effects on aggregate output, market concentration and unemployment. ${ }^{14}$ A regression is run using macroeconomic data of the first 30 years after market entry in the subset of green regimes.

\section{[Table 5 about here.]}

The first column in Table 5 shows the relation of policies, technological characteristics and the diffusion volatility $\sigma_{t}^{\nu}$ to aggregate output. The analysis indicates a negative relationship between aggregate output and $\sigma_{t}^{\nu}$. Also the investment subsidy $\varsigma^{i n v}$ and a lower entrant productivity $\beta^{A}$ exhibit a negative effect. $\varsigma^{i n v}$ distorts instantaneous investment decisions through the capital price channel. It reduces total investment costs while the other two instruments influence the relative cash-flow of using green capital. This might distort firms' choice about the investment quantity (cf. Hötte, 2020) and can be a source of inefficiency. The negative effect of $\beta^{A}$ on aggregate output is expectable. A higher $\beta^{A}$ indicates lower initial productivity of green capital. The marginal effect on aggregate output persists over time. $\beta^{b}$ is not significant. Lacking green skills have an impact on the transition probability, technological uncertainty and the macroeconomic performance in the short run, but this is overcome when the economy converges.

$\varsigma^{i n v}$ is associated with higher unemployment while technological uncertainty $\sigma_{t}^{\nu}$ tends to have a job-preserving effect. Stable technological pathways are associated with higher labor-saving productivity growth. This coincides with an increase in aggregate output and consumption but also with a moderate increase in unemployment. ${ }^{15}$ Technological uncertainty, reflected in $\sigma_{t}^{\nu}$, undermines the pace of productivity growth. This may preserve jobs in a closed economy.

$\varsigma^{i n v}$ is associated with higher unemployment which indicates a qualitative difference to the uncertainty-employment trade-off. Technological uncertainty is a coordination failure. It undermines aggregate productivity growth while individual investment decisions of firms are efficient given that the emerging regime is uncertain. In contrast, $\varsigma^{i n v}$ distorts investment decisions at the microlevel.

Technological uncertainty and less productive green capital (given that a transition occurs) allow less efficient firms to survive on the market. A high $\beta^{A}$ forces most productive firms to operate at a lower frontier if they adopt green technology. This reduces the productivity differences across firms and weakens competitive pressure. These effects are reflected in a lower market concentration

\footnotetext{
${ }^{14}$ Note that this is not a welfare analysis. This study does not account for the environmental effects. I refrain from analyzing the environmental effects because the highly stylized representation of technology in this model renders any trade-off between environmental and economic implications unreliable.

${ }^{15}$ Recall the time horizon of several decades that is considered in the simulations. The unemployment rate is an insufficient indicator to evaluate labor market effects over long time horizons (cf. Messenger et al., 2007; Bick et al., 2018).
} 
measured by the Herfindahl-index and a higher number of active firms.

The consumption subsidy $\varsigma^{\text {cons }}$ can be a driver of market concentration. It rewards firms most that adopted green technology early. If the transition is successful, these firms benefit twice. They have early specialized on the "right" technology type. This is associated with a competitive advantage if late adopters have to catch up. Further, they benefit from higher subsidy support which is proportional to $\nu_{i, t}^{g}$. This makes it possible to achieve higher mark-ups or to reduce prices. This double advantage makes it difficult for late adopters to sustain on the market.

Interactive properties $\chi^{\text {dist }}$ and $\chi^{\text {int }}$ are not significant. They operate through the channel of uncertainty. Their effect is ambiguous and dependent on the phase of the transition process. A higher $\chi^{\text {dist }}$ strengthens path dependence. Path dependence may operate in two directions. In the initial phase of green technology uptake, it operates in favor of the incumbent. This effect is reversed as soon as the green technology sufficiently diffused.

This analysis illustrates a trade-off between technological specialization and economic variety. Uncertainty undermines technological specialization which is a driver of productivity and output growth. At the same time, specialization makes it is difficult for weaker firms to survive.

\subsection{An economic interpretation of Geels and Schot's typology}

Different market-based policies exert different types of landscape pressure. The analysis shows that each type of pressure has its own idiosyncratic effect on the technological and economic evolution. It was shown that the effects of different pressure types are conditional on the characteristics of competing technology, namely the initial maturity of the emergent niche and cross-technology interactions in the learning process. This may explain the heterogeneity of observed transition curves and differences in the economic evolution.

Geels and Schot (2007) introduced a typology to classify four distinct transition pathways, i.e. (1) a transformation where the regime actors respond to pressure by gradually redirecting their technological pathway, (2) de- and re-alignment pathways where avalanche-like landscape pressure causes the dealignment of regime actors' activities and multiple, emergent niches incrementally align their activities to form a new regime, (3) technological substitution in which a sudden landscape shock allows a sufficiently mature niche to gain momentum and replace the regime and (4) a reconfiguration pathway where symbiotic innovations developed in market niches gradually, but profoundly transform the incumbent regime. The authors explain the heterogeneity of pathways by the timing and nature of multi-level interactions.

In this paper, concepts of MLP are captured by economic variables. Geels and Schot's timing of interaction is operationalized as relative maturity of the entrant technology (SF1) and its timely coincidence with pressure from the landscape (SF3). The analysis of the landscape interaction is limited to the policy experiment, but the modeling framework can be straightforwardly generalized. Its timing of interaction was not studied. 
The nature of interaction refers to dominant agents' capacity to cope with technological novelty and landscape pressure. In the model, the agents are technology adopting firms whose dominance in the market (proxied e.g. by firm size and market shares) depends on their (technology-specific) productivity. The technological distance and difficulty describe how easily the emergent green technology can be integrated in pre-existing production routines and determine the strength of path dependence (cf. SF2).

The nature of landscape-regime interactions is given by regime agents' capacity to cope with external pressure. In the model, landscape pressure comes from the cost of natural resource inputs. Incremental innovation in the incumbent technology may alleviate the pressure (e.g. when the incumbent technology becomes more efficient), but this was not explicitly studied in this paper.

The type of emerging pathway is reflected in the composite of different economic and technological variables, mainly in the shape of the diffusion curve, transition costs and changes in the market structure. Other variables can be added. The simulations show that the stability of the transition process is decisive for the degree of disruption. It depends agents' ability to cope with new technology (SF4).

Following Geels and Schot's typology, a smooth diffusion curve accompanied by minor disruptions in the market structure and low transition costs can be interpreted as transformation pathway. Agents gradually replace conventional by green technology without struggling with the incompatibility of pre-existing know-how. A similar diffusion curve may be observed when the transition follows a reconfiguration pathway but in this case existing know-how renders obsolete and is gradually replaced by a new type, i.e. when technological knowledge is very dissimilar, but easy and quick to learn.

A highly volatile diffusion pattern associated with high transition costs and major disruptions in the market structure can be interpreted as de- and realignment. The niche is not sufficiently mature to gain momentum, but regime pressure is sufficiently strong to disrupt the regime. A prolonged period of technological uncertainty results in which regime and entrant technologies coexist. The case of a rapid and smooth diffusion can be interpreted as substitution pathway. Landscape pressure is sufficiently strong to allow a mature niche technology to gain momentum and to replace the regime.

This operationalization of Geels and Schot's typology is a purely economic interpretation and limited to technology-adopting firms as level of analysis. The proposed framework simplifies some dimensions of MLP that may follow different dynamics. For example, norms and habits that shape consumer behavior are only partially absorbed by the landscape but have not been elaborated in detail. This framework is not aimed at capturing the full complexity of MLP. Rather, it is aimed at narrowing down the complex framework to make it tractable for economic analyses. The suitability of this simplification needs to be demonstrated in practice which is beyond the scope of this paper. Extensions and generalizations of the proposed modeling framework to study e.g. other configurations of landscape pressure or multiple competing technologies are feasible. 


\section{Concluding remarks}

In this paper, I introduce a conceptual framework for the characterization of competing technologies that is based on four stylized facts from the literature. This framework builds the basis for the technology-concept in the macroeconomic ABMEurace@unibi-eco that is used to study transition pathways. It is an economic approach to the MLP that operationalizes the technological regime as the composite of technology and firms that dominate the market under the given technology choice.

It was seen how the relative endowment of technology-specific knowledge influences individual adoption behavior (SF1). Insufficient know-how of adopters and a lower technical maturity of supplied technology can be adoption barriers. Cross-technology interactions influence the relative pace at which relative stocks of technology-specific knowledge are accumulated (SF2). In the model, interactions between the niche and regime are operationalized as technological distance and technical difficulty. These properties describe the capacity of agents, that are successful under the incumbent technological regime, to cope with new technology.

The market entry of an emergent niche is facilitated by exogenous landscape conditions (SF3) that are operationalized as price of a natural resource input to operate the incumbent technology. The market entry can trigger the transition to the new technology. The simulation results show how the degree of disruption of the transition differs across different pathways and can be measured by the stability of the transition curve, learning costs and changes in the market structure. It can be explained by regime actors' capacity to cope with new technology (SF4).

This paper adds a comprehensive macroeconomic framework to the literature of transition modeling. In contrast to existing (economic) models of transitions (cf. Köhler et al., 2018), it enables not only the study of the process of technology replacement, but also the evaluation of broader macroeconomic consequences of technology transitions. The agent-based methodology enables the simulation of non-linear feedback loops emerging from the interaction of heterogeneous agents consistently. Modeling sustainability transitions provides a clearly structured and systematic approach to investigate transition dynamics scientifically. It enables the execution of (policy) experiments and to understand complex interdependencies of subsystems. This might be informative to identify bottlenecks and levers to change. The proposed framework offers a formalization of transition pathways in economic variables that can be systematically linked to empirical quantitative data. This might be a theoretical basis for empirical studies.

The insights of this study may improve the economic understanding of possible transition pathways, macroeconomic side effects and disruptions. This understanding is critical for policy makers and contributes to an informed societal

dialogue across and within the boundaries of scientific disciplines (cf. Rosenbloom, 2017; Holtz et al., 2015). 


\section{Acknowledgements}

This work uses a modified version of the Eurace@Unibi model, developed by Herbert Dawid, Simon Gemkow, Philipp Harting, Sander van der Hoog and Michael Neugart, as an extension of the research within the EU 6th Framework Project Eurace. Particular gratitude is owed to Herbert Dawid, Matthias Endres, Philipp Harting, Antoine Mandel and two anonymous reviewers. The author thankfully acknowledges financial support by the German National Academic Foundation, the Deutsch-französische Hochschule and the Bielefeld Graduate School of Economics and Management. Thanks to the Center for Research Data Management at Bielefeld University. The author gratefully acknowledges the provision of free statistical software maintained by the $\mathrm{R}$ programming community.

\section{References}

\section{References}

Acemoglu, D., 2002. Directed technical change. The Review of Economic Studies 69, 781-809. doi:10.1111/1467-937X.00226.

Acemoglu, D., Akcigit, U., Kerr, W.R., 2016. Innovation network. Proceedings of the National Academy of Sciences 113, 11483-11488. doi:0.1073/pnas . 1613559113.

Adner, R., Kapoor, R., 2016. Innovation ecosystems and the pace of substitution: Re-examining technology s-curves. Strategic management journal 37, 625-648. doi:10.1002/smj. 2363.

Aghion, P., Dechezleprêtre, A., Hemous, D., Martin, R., Van Reenen, J., 2016. Carbon taxes, path dependency, and directed technical change: Evidence from the auto industry. Journal of Political Economy 124, 1-51. doi:10.1086/ 684581 .

Allan, C., Jaffe, A.B., Sin, I., 2014. Diffusion of green technology: a survey. Motu Working Paper No. 14-04. doi:10.2139/ssrn. 2422682.

Altenburg, T., Schamp, E.W., Chaudhary, A., 2015. The emergence of electromobility: Comparing technological pathways in France, Germany, China and India. Science and Public Policy 43, 464-475. doi:10.1093/scipol/scv054.

Ambec, S., Cohen, M.A., Elgie, S., Lanoie, P., 2013. The Porter hypothesis at 20: can environmental regulation enhance innovation and competitiveness? Review of Environmental Economics and Policy 7, 2-22. doi:10.1093/reep/res016.

Arthur, W.B., 1989. Competing technologies, increasing returns, and lock-in by historical events. The Economic Journal 99, 116-131. doi:10.2307/2234208. 
Arundel, A., Kemp, R., 2009. Measuring eco-innovation. UNU-Merit - Working Paper Series 2009-017.

Autor, D.H., Levy, F., Murnane, R.J., 2003. The skill content of recent technological change: An empirical exploration. The Quarterly Journal of Economics 118, 1279-1333. doi:10.1162/003355303322552801.

Behera, K.K., Alam, A., Vats, S., Sharma, H.P., Sharma, V., 2012. Organic Farming History and Techniques. Springer Netherlands, Dordrecht. pp. 287328. doi:10.1007/978-94-007-1905-7_12.

Belz, F.M., 2004. A transition towards sustainability in the Swiss agri-food chain (1970-2000): using and improving the multi-level perspective, in: Elzen, B., Geels, F., Green, K. (Eds.), System innovation and the transition to sustainability: Theory, evidence and policy. Edward Elgar, Cheltenham, pp. $97-114$.

Berkeley, N., Bailey, D., Jones, A., Jarvis, D., 2017. Assessing the transition towards battery electric vehicles: A multi-level perspective on drivers of, and barriers to, take up. Transportation Research Part A: Policy and Practice 106, 320-332. doi:10.1016/j.tra.2017.10.004.

Bick, A., Fuchs-Schündeln, N., Lagakos, D., 2018. How do hours worked vary with income? cross-country evidence and implications. American Economic Review 108, 170-99. doi:10.1257/aer.20151720.

Boehm, J., Dhingra, S., Morrow, J., et al., 2016. Swimming upstream: inputoutput linkages and the direction of product adoption. CEP Discussion Paper, No. 1407.

Breschi, S., Malerba, F., Orsenigo, L., 2000. Technological regimes and Schumpeterian patterns of innovation. The Economic Journal 110, 388-410. doi:10.1111/1468-0297.00530.

Carvalho, V.M., Voigtländer, N., 2014. Input diffusion and the evolution of production networks. National Bureau of Economic Research, Working Paper No. w20025. doi:10.3386/w20025.

Cohen, W.M., Levinthal, D.A., 1990. Absorptive capacity: A new perspective on learning and innovation. Administrative Science Quarterly 35, 128-152. doi: $10.2307 / 2393553$.

Comin, D., Hobijn, B., Rovito, E., 2006. Five facts you need to know about technology diffusion. National Bureau of Economic Research, Working Paper No. w11928. doi:10.3386/w11928.

Consoli, D., Marin, G., Marzucchi, A., Vona, F., 2016. Do green jobs differ from non-green jobs in terms of skills and human capital? Research Policy 45, 1046-1060. doi:10.1016/j.respol.2016.02.007. 
Cowan, R., 1991. Tortoises and hares: choice among technologies of unknown merit. The economic journal 101, 801-814.

Cowan, R., David, P.A., Foray, D., 2000. The explicit economics of knowledge codification and tacitness. Industrial and Corporate Change 9, 211-253. doi:10.1093/icc/9.2.211.

Dawid, H., 2006. Agent-based Models of Innovation and Technological Change, in: Tesfatsion, L., Judd, K. (Eds.), Handbook of Computational Economics, Volume II: Agent-Based Computational Economics. Elsevier. chapter 25, pp. 1235-1272. doi:10.1016/S1574-0021(05)02025-3.

Dawid, H., Gemkow, S., 2013. How do social networks contribute to wage inequality? Insights from an agent-based analysis. Industrial and Corporate Change 23, 1171-1200. doi:10.1093/icc/dtt049.

Dawid, H., Gemkow, S., Harting, P., van der Hoog, S., Neugart, M., 2011. Eurace@Unibi Model v1.0 User Manual. Technical Report. Bielefeld University.

Dawid, H., Harting, P., van der Hoog, S., Neugart, M., 2019a. Macroeconomics with heterogeneous agent models: fostering transparency, reproducibility and replication. Journal of Evolutionary Economics 29, 467-538. doi:10.1007/ s00191-018-0594-0.

Dawid, H., Harting, P., Neugart, M., 2018. Cohesion policy and inequality dynamics: Insights from a heterogeneous agents macroeconomic model. Journal of Economic Behavior \& Organization 150, 220-255. doi:10.1016/j.jebo. 2018.03 .015 .

Dawid, H., Harting, P., Neugart, M., 2019b. The Role of (De-) Centralized Wage Setting for Industry Dynamics and Economic Growth: An AgentBased Analysis with the Eurace@ Unibi Model. Bielefeld Working Papers in Economics and Management No. 06-2019. doi:10.2139/ssrn.3383351.

Dechezleprêtre, A., Glachant, M., Haščič, I., Johnstone, N., Ménière, Y., 2011. Invention and transfer of climate change-mitigation technologies: a global analysis. Review of environmental economics and policy 5, 109-130. doi:10. 1093/reep/req023.

Di Stefano, G., Gambardella, A., Verona, G., 2012. Technology push and demand pull perspectives in innovation studies: Current findings and future research directions. Research Policy 41, 1283-1295. doi:10.1016/j.respol.2012.03. 021.

Dosi, G., 1982. Technological paradigms and technological trajectories: a suggested interpretation of the determinants and directions of technical change. Research Policy 11, 147-162. doi:10.1016/0048-7333(82) 90016-6.

Dosi, G., 1988. The nature of the innovative process, in: Technical Change and Economic Theory. Pinter Publishers. 
Dosi, G., 1991. The research on innovation diffusion: An assessment, in: Diffusion of technologies and social behavior. Springer, pp. 179-208. doi:10.1007/ 978-3-662-02700-4_7.

Ehret, O., Dignum, M., 2012. Introducing hydrogen and fuel cell vehicles in Germany, in: Routledge studies in Sustainability Transitions, in: Geels, F., Kemp, R., Dudley, G., Lyons, G. (Eds.), Automobility in transition?: A socio-technical analysis of sustainable transport. Routledge. volume part 2: Automobility in Transition.

Fu, X., Zhang, J., 2011. Technology transfer, indigenous innovation and leapfrogging in green technology: the solar-pv industry in china and india. Journal of Chinese Economic and Business Studies 9, 329-347. doi:10.1080/14765284. 2011.618590 .

Geels, F.W., 2002. Technological transitions as evolutionary reconfiguration processes: a multi-level perspective and a case-study. Research policy 31, 1257-1274. doi:10.1016/S0048-7333(02)00062-8.

Geels, F.W., 2005. The dynamics of transitions in socio-technical systems: a multi-level analysis of the transition pathway from horse-drawn carriages to automobiles (1860-1930). Technology analysis \& strategic management 17, 445-476. doi:10.1080/09537320500357319.

Geels, F.W., Kemp, R., Dudley, G., Lyons, G., 2011. Automobility in transition?: A socio-technical analysis of sustainable transport. Routledge Studies in Sustainability Transitions, Routledge.

Geels, F.W., Kern, F., Fuchs, G., Hinderer, N., Kungl, G., Mylan, J., Neukirch, M., Wassermann, S., 2016. The enactment of socio-technical transition pathways: a reformulated typology and a comparative multi-level analysis of the German and UK low-carbon electricity transitions (1990-2014). Research Policy 45, 896-913. doi:10.1016/j.respol.2016.01.015.

Geels, F.W., Schot, J., 2007. Typology of sociotechnical transition pathways. Research policy 36, 399-417. doi:10.1016/j.respol.2007.01.003.

Gillingham, K., Newell, R.G., Pizer, W.A., 2008. Modeling endogenous technological change for climate policy analysis. Energy Economics 30, 2734-2753. doi:10.1016/j.eneco.2008.03.001.

Grübler, A., 1991. Diffusion: long-term patterns and discontinuities, in: Diffusion of Technologies and Social Behavior. Springer, pp. 451-482. doi:10.1007/ 978-3-662-02700-4_18.

Harting, P., 2019. Macroeconomic stabilization and long-term growth: The role of policy design. Macroeconomic Dynamics , 1-46doi:10.1017/ S1365100519000488. 
Herrmann, J.K., Savin, I., 2017. Optimal policy identification: Insights from the german electricity market. Technological forecasting and social change 122, $71-90$.

Holtz, G., Alkemade, F., De Haan, F., Köhler, J., Trutnevyte, E., Luthe, T., Halbe, J., Papachristos, G., Chappin, E., Kwakkel, J., et al., 2015. Prospects of modelling societal transitions: Position paper of an emerging community. Environmental Innovation and Societal Transitions 17, 41-58. doi:10.1016/j . eist.2015.05.006.

van der Hoog, S., Dawid, H., 2017. Bubbles, crashes, and the financial cycle: the impact of banking regulation on deep recessions. Macroeconomic Dynamics , 1-42doi:10.1017/S1365100517000219.

Hötte, K., 2019a. Data publication: Skill transferability and the adoption of new technology: A learning based explanation for patterns of diffusion. Data Publication. Bielefeld University. doi:10.4119/unibi/2935425.

Hötte, K., 2019b. Eurace@unibi-eco: A model of technology transitions, v1.1, Model documentation. Bielefeld Working Papers in Economics and Management No. 08-2019. Bielefeld University. doi:10.4119/unibi/2935928.

Hötte, K., 2019c. How to accelerate green technology diffusion? An agent-based approach to directed technological change with coevolving absorptive capacity. Bielefeld Working Papers in Economics and Management No. 01-2019. Bielefeld University. doi:10.2139/ssrn. 3312654.

Hötte, K., 2019d. Skill Transferability and the Stability of Transition PathwaysA Learning-Based Explanation for Patterns of Diffusion. Bielefeld Working Papers in Economics and Management No. 09-2019. Bielefeld University. doi:10.4119/unibi/2936212.

Hötte, K., 2020. How to accelerate green technology diffusion? directed technological change in the presence of coevolving absorptive capacity. Energy Economics 85, 104565. doi:10.1016/j. eneco.2019.104565.

Høyer, K.G., 2008. The history of alternative fuels in transportation: The case of electric and hybrid cars. Utilities Policy 16, 63-71. doi:10.1016/j.jup. 2007.11 .001$.

Huang, J.J., et al., 2018. Technology Network, Innovation and Growth. Society for Economic Dynamics Meeting Papers No. 178.

IPCC, 2018. Summary for Policymakers, in: Masson-Delmotte, V., Zhai, P., Pörtner, H., Roberts, D., Skea, J., Shukla, P.R., Pirani, A., Moufouma-Okia, W., Péan, C., Pidcock, R., Connors, S., Matthews, J.B.R., Chen, Y., Zhou, X., Gomis, M.I., Lonnoy, E., Maycock, T., Tignor, M., Waterfield, T. (Eds.), An IPCC Special Report on the impacts of global warming of $1.5^{\circ} \mathrm{C}$ above pre-industrial levels and related global greenhouse gas emission pathways, 
in the context of strengthening the global response to the threat of climate change, sustainable development, and efforts to eradicate poverty, Summary for Policymakers. World Meteorological Organization, Geneva, Switzerland.

Jaffe, A.B., De Rassenfosse, G., 2017. Patent citation data in social science research: Overview and best practices. Journal of the Association for Information Science and Technology 68, 1360-1374. doi:10.1002/asi.23731.

Jiang, H., Lu, F., 2018. To be friends, not competitors: A story different from Tesla driving the Chinese automobile industry. Management and Organization Review 14, 491-499. doi:10.1017/mor.2018.34.

Jones, G.G., Bouamane, L., 2011. Historical trajectories and corporate competences in wind energy. Harvard Business School Working Paper, No. 11-112.

Jones, G.G., Bouamane, L., 2012. " Power from Sunshine": A Business History of Solar Energy. Harvard Business School Working Paper, No. 12-105.

Kemfert, C., Gawel, E., Fischedick, M., Bettzüge, M.O., Matthes, F.C., Kuhlmann, A., 2018. Klimaziel 2020 verfehlt: Zeit für eine neuausrichtung der klimapolitik? ifo Schnelldienst 71, 3-25.

Kemp, R., 1994. Technology and the transition to environmental sustainability: the problem of technological regime shifts. Futures 26, 1023-1046. doi:10. 1016/0016-3287 (94) 90071-X.

Kemp, R., Volpi, M., 2008. The diffusion of clean technologies: a review with suggestions for future diffusion analysis. Journal of Cleaner Production 16, 14-21. doi:10.1016/j.jclepro.2007.10.019.

Klimek, P., Hausmann, R., Thurner, S., 2012. Empirical confirmation of creative destruction from world trade data. PloS ONE 7, e38924. doi:10.1371/journal. pone. 0038924.

Köhler, J., De Haan, F., Holtz, G., Kubeczko, K., Moallemi, E., Papachristos, G., Chappin, E., 2018. Modelling sustainability transitions: An assessment of approaches and challenges. Journal of Artificial Societies and Social Simulation 21. doi:10.18564/jasss. 3629.

Köhler, J., Geels, F.W., Kern, F., Markard, J., Onsongo, E., Wieczorek, A., Alkemade, F., Avelino, F., Bergek, A., Boons, F., et al., 2019. An agenda for sustainability transitions research: State of the art and future directions. Environmental Innovation and Societal Transitions doi:10.1016/j . eist. 2019. 01.004 .

Köhler, J., Grubb, M., Popp, D., Edenhofer, O., 2006. The transition to endogenous technical change in climate-economy models: a technical overview to the innovation modeling comparison project. The Energy Journal , 1755doi:10.5547/ISSN0195-6574-EJ-VolSI2006-NoSI1-2. 
Korzinov, V., Savin, I., 2018. General purpose technologies as an emergent property. Technological Forecasting and Social Change 129, 88-104. doi:10 . 1016/j.techfore.2017.12.011.

Kuhn, M., 2018. caret: Classification and Regression Training. Technical Report. URL: https : //CRAN.R-project.org/package=caret. r package version 6.081.

Lachman, D.A., 2013. A survey and review of approaches to study transitions. Energy Policy 58, 269-276. doi:10.1016/j.enpol.2013.03.013.

Lema, R., Lema, A., 2012. Technology transfer? the rise of china and india in green technology sectors. Innovation and Development 2, 23-44. doi:10.1080/ 2157930X.2012.667206.

Lemoine, D., 2018. Innovation-led transitions in energy supply. National Bureau of Economic Research, Working Paper No. w23420. doi:10.3386/w23420.

Lockeretz, W., 2007. Organic farming: an international history. CABI.

Ma, S.m., Sauerborn, J., 2006. Review of History and Recent Development of Organic Farming Worldwide. Agricultural Sciences in China 5, 169 - 178. doi:10.1016/S1671-2927(06)60035-7.

Malerba, F., Nelson, R., Orsenigo, L., Winter, S., 1999. 'history-friendly'models of industry evolution: the computer industry. Industrial and corporate change 8, 3-40. doi:10.1093/icc/8.1.3.

Messenger, J.C., Lee, S., McCann, D., 2007. Working time around the world: Trends in working hours, laws, and policies in a global comparative perspective. Routledge.

Metcalfe, J., 1988. The diffusion of innovations: an interpretive study, in: Dosi, G., Freeman, C., Nelson, R., Silverberg, G., Soete, L. (Eds.), Technical Change and Economic Theory. Pinter.

Moallemi, E.A., de Haan, F.J., 2019. Modelling Transitions: Virtues, Vices, Visions of the Future. Routledge.

Nelson, R.R., Winter, S.G., 1977. In search of useful theory of innovation. Research Policy 6, 36-76. doi:10.1007/978-3-0348-5867-0_14.

Nelson, R.R., Winter, S.G., 1982. An evolutionary theory of economic change. Belknap Press of Harvard University Press.

Neukirch, M., 2009. Die internationale Pionierphase der Windenergienutzung. Dissertation. Niedersächsische Staats-und Universitätsbibliothek Göttingen.

Nijkamp, P., Wang, S., Kremers, H., 2005. Modeling the impacts of international climate change policies in a CGE context: The use of the GTAP-E model. Economic Modelling 22, 955-974. doi:10.1016/j .econmod.2005.06.001. 
Nordensvärd, J., Urban, F., 2015. The stuttering energy transition in germany: Wind energy policy and feed-in tariff lock-in. Energy Policy 82, 156-165. doi:10.1016/j.enpol.2015.03.009.

Oikawa, K., 2017. Inter-firm Technological Proximity and Knowledge Spillovers. Tokyo Center for Economic Research (TCER) Paper No. E-114.

Pahle, M., 2010. Germany's dash for coal: Exploring drivers and factors. Energy Policy 38, 3431-3442. doi:10.1016/j.enpol.2010.02.017.

Pan, M., Zhou, Y., Zhou, D.K., 2017. Comparing the innovation strategies of Chinese and European wind turbine firms through a patent lens. Environmental Innovation and Societal Transitions doi:10.1016/j.eist.2017.12.003.

Pfeiffer, B., Mulder, P., 2013. Explaining the diffusion of renewable energy technology in developing countries. Energy Economics 40, 285-296. doi:10. 1016/j.eneco.2013.07.005.

Pizer, W.A., Popp, D., 2008. Endogenizing technological change: Matching empirical evidence to modeling needs. Energy Economics 30, 2754-2770. doi:10.1016/j.eneco. 2008.02.006.

Popp, D., 2019. Environmental policy and innovation: a decade of research. National Bureau of Economic Research, Working Paper No. w25631. doi:10. $3386 /$ w25631.

Popp, D., Newell, R.G., Jaffe, A.B., 2010. Energy, the environment, and technological change, in: Hall, B., Rosenberg, N. (Eds.), Handbook of the Economics of Innovation. Elsevier. volume 2, pp. 873-937. doi:10.1016/ S0169-7218(10)02005-8.

Quitzow, R., 2015. Dynamics of a policy-driven market: The co-evolution of technological innovation systems for solar photovoltaics in China and Germany. Environmental Innovation and Societal Transitions 17, 126-148. doi:10.1016/j.eist.2014.12.002.

R Core Team, 2018. R: A Language and Environment for Statistical Computing. Technical Report. Vienna, Austria. URL: https://www.R-project.org/.

Reganold, J.P., Wachter, J.M., 2016. Organic agriculture in the twenty-first century. Nature plants 2, 15221. doi:10.1038/nplants.2015.221.

Romer, P.M., 1990. Endogenous technological change. Journal of political Economy 98, S71-S102. doi:10.1086/261725.

Rosenbloom, D., 2017. Pathways: An emerging concept for the theory and governance of low-carbon transitions. Global Environmental Change 43, 37-50. doi:10.1016/j.gloenvcha.2016.12.011. 
Safarzyńska, K., Frenken, K., van den Bergh, J.C., 2012. Evolutionary theorizing and modeling of sustainability transitions. Research Policy 41, 1011-1024. doi:10.1016/j.respol.2011.10.014.

Simon, H.A., 1957. Administrative Behavior: A Study of Decision Making Processes in Administrative Organization. New York: Wiley.

Smith, A., Voß, J.P., Grin, J., 2010. Innovation studies and sustainability transitions: The allure of the multi-level perspective and its challenges. Research policy 39, 435-448. doi:10.1016/j.respol.2010.01.023.

Stasinopoulos, M.D., Rigby, R.A., Heller, G.Z., Voudouris, V., De Bastiani, F., 2017. Flexible regression and smoothing: using GAMLSS in R. Chapman and Hall/CRC.

Steffen, W., Rockström, J., Richardson, K., Lenton, T.M., Folke, C., Liverman, D., Summerhayes, C.P., Barnosky, A.D., Cornell, S.E., Crucifix, M., et al., 2018. Trajectories of the Earth System in the Anthropocene. Proceedings of the National Academy of Sciences 115, 8252-8259. doi:10.1073/pnas. 1810141115.

Triguero, A., Moreno-Mondéjar, L., Davia, M.A., 2013. Drivers of different types of eco-innovation in European SMEs. Ecological Economics 92, 25-33. doi:10.1016/j.ecolecon.2013.04.009.

Tushman, M.L., Anderson, P., 1986. Technological discontinuities and organizational environments. Administrative Science Quarterly , 439-465.

Tyfield, D., Zuev, D., 2018. Stasis, dynamism and emergence of the e-mobility system in china: A power relational perspective. Technological Forecasting and Social Change 126, 259-270. doi:10.1016/j.techfore.2017.09.006.

Unruh, G.C., 2000. Understanding carbon lock-in. Energy Policy 28, 817-830. doi:10.1016/S0301-4215(00)00070-7.

Venables, W.N., Ripley, B.D., 2002. Modern Applied Statistics with S. 4th ed., Springer, New York. URL: http://www.stats.ox.ac.uk/pub/MASS4.

Vona, F., Marin, G., Consoli, D., Popp, D., 2015. Green skills. National Bureau of Economic Research Working Paper. National Bureau of Economic Research. doi:10.3386/w21116.

Watson, G., 1971. Resistance to change. American Behavioral Scientist 14, 745-766. doi:10.1177/000276427101400507.

Wells, P., Nieuwenhuis, P., 2012. Transition failure: Understanding continuity in the automotive industry. Technological Forecasting and Social Change 79, 1681-1692. doi:10.1016/j.techfore.2012.06.008. 
Wesseling, J., Farla, J., Hekkert, M., 2015. Exploring car manufacturers' responses to technology-forcing regulation: The case of california's zev mandate. Environmental Innovation and Societal Transitions 16, 87-105. doi:10.1016/j.eist. 2015.03 .001 .

Windrum, P., 1999. Simulation models of technological innovation. American Behavioral Scientist 42, 1531-1550. doi:10.1177/00027649921957874.

Yuan, J., Xu, Y., Hu, Z., 2012. Delivering power system transition in China. Energy Policy 50, 751-772. doi:10.1016/j.enpol.2012.08.024. 


\section{Tables and figures}

\subsection{Tables}

Table 1: Glossary of parameters and variables in Eurace@unibi-eco

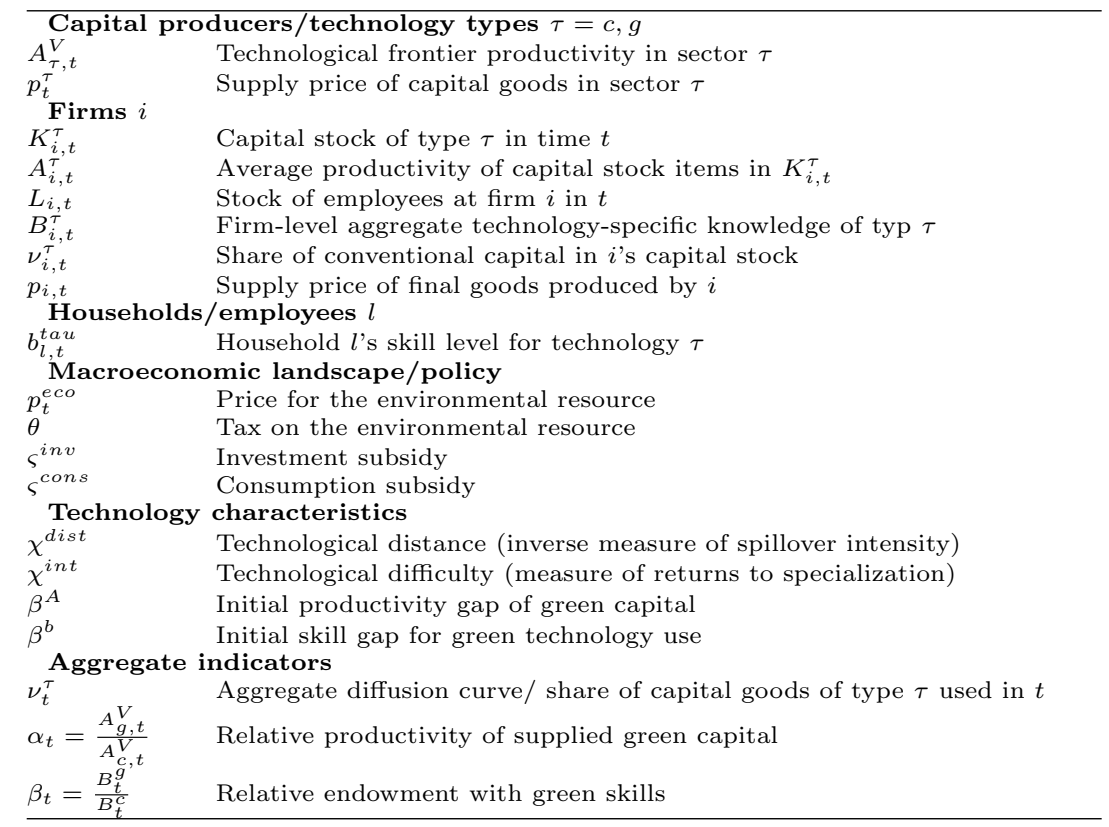

Table 2: Initialization (baseline)

\begin{tabular}{r|cccc} 
& Mean (Std) & $\begin{array}{c}\text { eco } \\
\text { Mean }(\text { Std })\end{array}$ & $\begin{array}{c}\text { conv } \\
\text { Mean }(\text { Std) }\end{array}$ & p-value \\
\hline$\beta^{A}$ & $.0495(.0306)$ & $.0358(.0266)$ & $.0564(.0301)$ & $6.4 \mathrm{e}-6$ \\
$\beta^{b}$ & $.0482(.0283)$ & $.0323(.0231)$ & $.0561(.0274)$ & $8.9 \mathrm{e}-9$ \\
$\chi^{\text {int }}$ & $.9942(.5563)$ & $1.044(.5635)$ & $.9694(.5531)$ & .3715 \\
$\chi^{\text {dist }}$ & $.4878(.2916)$ & $.4075(.2866)$ & $.5279(.2868)$ & .0041
\end{tabular}

The column at the left hand side shows the mean (standard deviation) of initial conditions across all runs. The other two columns show the initial conditions computed as averages within the subset of green and conventional regimes. The p-value indicates whether the technological regimes significantly differ by initial conditions. 
Table 3: Stylized facts as design and validation criteria

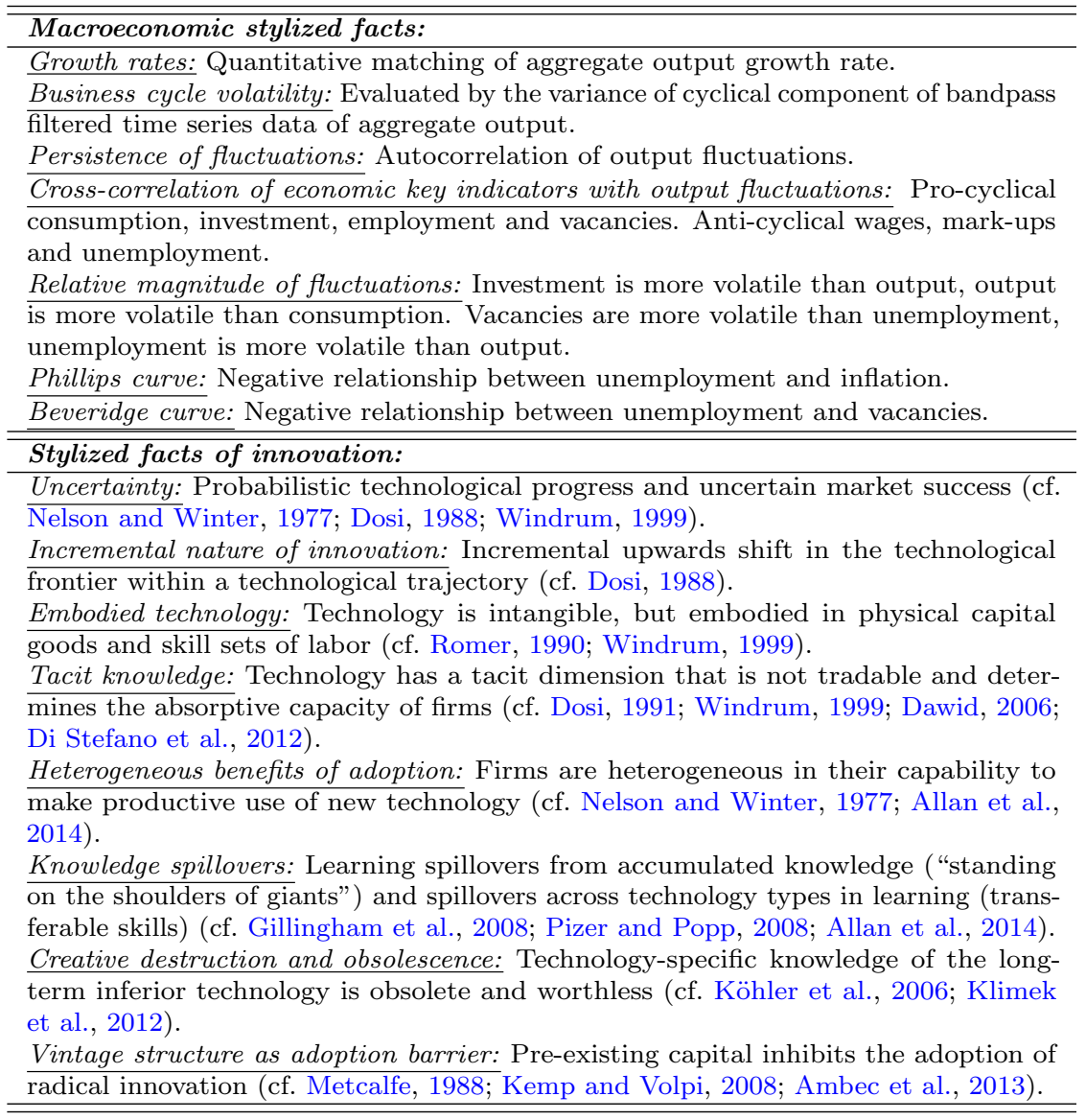

This table is taken from Hötte (2020). The macroeconomic validation scenario are a selection of criteria used and described in more detail in Dawid et al. (2018). In the more comprehensive model documentation in Hötte (2019b), it is shown how the model matches these stylized facts.

Table 4: Regression of transition pathways on technology characteristics

\begin{tabular}{|c|c|c|c|c|c|c|c|}
\hline \multicolumn{2}{|c|}{ Dependent variable } & $\begin{array}{l}\nu_{i}^{c} \\
\text { OLS }\end{array}$ & $\begin{array}{l}\nu_{i}^{c} \\
\text { Probit }\end{array}$ & $\begin{array}{l}t_{i}^{*} \\
\mathrm{IV}\end{array}$ & $\begin{array}{l}\left(\frac{A_{i}^{+}}{A_{i}^{-}}\right)^{*} \\
\mathrm{IV}^{*}\end{array}$ & $\begin{array}{l}\left(\frac{B_{i}^{+}}{B_{i}^{-}}\right)^{*} \\
\mathrm{IV}^{2}\end{array}$ & $\begin{array}{l}\left(\sigma_{i}^{\nu}\right)^{2} \\
\mathrm{IV}\end{array}$ \\
\hline (1) & (Intercept) & $\begin{array}{l}.3381 * * * \\
(.0043)\end{array}$ & $\begin{array}{l}-.4684 * * * \\
(.0144)\end{array}$ & $\begin{array}{l}3794^{* * * *} \\
(70.63)\end{array}$ & $\begin{array}{l}1.099 * * * \\
(.0031)\end{array}$ & $\begin{array}{l}1.097^{* * *} \\
(.0029)\end{array}$ & $\begin{array}{l}6.548^{* * *} \\
(.1399)\end{array}$ \\
\hline (2) & $\chi^{d i s t}$ & $\begin{array}{l}.0130 * * \\
-.0130^{*} \\
(.0044)\end{array}$ & $\begin{array}{l}.0898^{* * * *} \\
(.0151)\end{array}$ & $\begin{array}{l}-471.0^{* * *} \\
(65.99)\end{array}$ & $\begin{array}{l}.0141 * * * \\
(.0041)\end{array}$ & $\begin{array}{l}.0213 * * * \\
(.0031)\end{array}$ & $\begin{array}{l}-.9603 * * * \\
(.1172)\end{array}$ \\
\hline (3) & $\chi^{i n t}$ & $\begin{array}{l}.0081 . \\
(.0043)\end{array}$ & $\begin{array}{l}-.0161 \\
(.0145)\end{array}$ & $\begin{array}{l}-117.2^{* * *} \\
(31.42)\end{array}$ & $\begin{array}{l}.0085 * * * \\
(.0017)\end{array}$ & $\begin{array}{l}.0078^{* * *} * \\
(.0012)\end{array}$ & $\begin{array}{l}-.0240 \\
(.0535)\end{array}$ \\
\hline (4) & $\theta$ & $\begin{array}{l}-.0300 * * * \\
(.0043)\end{array}$ & $\begin{array}{l}-.1119 * * * \\
(.0145)\end{array}$ & $\begin{array}{l}788.9^{* * *} \\
(70.37)\end{array}$ & $\begin{array}{l}-.0297^{* * *} \\
(.0037)\end{array}$ & $\begin{array}{l}-.0296 * * * \\
(.0029)\end{array}$ & $\begin{array}{l}2.267^{* * *} \\
(.1218)\end{array}$ \\
\hline (5) & $\varsigma^{\text {cons }}$ & $\begin{array}{l}-.0401 * * * \\
(.0044)\end{array}$ & $\begin{array}{l}-.1730^{* * *} \\
(.0151)\end{array}$ & $\begin{array}{l}-318.1 * * * \\
(77.99)\end{array}$ & $\begin{array}{l}.0085^{* * *} * \\
(.0018)\end{array}$ & $\begin{array}{l}-.0065^{*} \\
(.0032)\end{array}$ & $\begin{array}{l}-.1806 * * * \\
(.0536)\end{array}$ \\
\hline (6) & $\varsigma^{i n v}$ & $\begin{array}{l}-.0205^{* * *} \\
(.0045)\end{array}$ & $\begin{array}{l}-.0763^{* * *} \\
(.0149)\end{array}$ & $\begin{array}{l}-310.8^{* * *} \\
(58.73)\end{array}$ & $\begin{array}{l}-.0369 * * * \\
(.0037)\end{array}$ & $\begin{array}{l}-.0286 * * * \\
(.0030)\end{array}$ & $\begin{array}{l}1.506^{* * *} \\
(.1090)\end{array}$ \\
\hline (7) & $\beta^{A}$ & $\begin{array}{l}.1139 * * * \\
(.0046)\end{array}$ & $\begin{array}{l}.4650^{* * *} \\
(.0196)\end{array}$ & $\begin{array}{l}8.747 \\
(27.75)\end{array}$ & $\begin{array}{l}.0395^{* * *} \\
(.0049)\end{array}$ & $\begin{array}{l}.0069 * * * \\
(.0016)\end{array}$ & $\begin{array}{l}-.3212^{* * *} \\
(.0482)\end{array}$ \\
\hline (8) & $\beta^{b}$ & $\begin{array}{l}.0946^{* * *} \\
(.0044)\end{array}$ & $\begin{array}{l}.2974 * * * \\
(.0149)\end{array}$ & $\begin{array}{l}-501.0^{* * *} \\
(65.63)\end{array}$ & $\begin{array}{l}.0478^{* * *} \\
(.0040)\end{array}$ & $\begin{array}{l}.0519 * * * \\
(.0035)\end{array}$ & $\begin{array}{l}-2.894^{* * *} \\
(.1436)\end{array}$ \\
\hline (9) & $\chi^{d i s t} \cdot \theta$ & $\begin{array}{l}-.0504 * * * \\
(.0044)\end{array}$ & $\begin{array}{l}-.1177 * * * \text { JU } \\
(.0149)\end{array}$ & $\begin{array}{l}-119.3^{* * *} \\
(28.46)\end{array}$ & $\begin{array}{l}-.0110^{* * *} \\
(.0019)\end{array}$ & $\begin{array}{l}-.0063 * * * \\
(.0014)\end{array}$ & $\begin{array}{l}.4541^{* * * *} \\
(.0609)\end{array}$ \\
\hline (10) & $\chi^{i n t} \cdot \theta$ & $\begin{array}{l}.0460 * * * \\
(.0040)\end{array}$ & $\begin{array}{l}.1706^{* * * *} \\
(.0137)\end{array}$ & $\begin{array}{l}-143.2^{* * *} \\
(28.06)\end{array}$ & & & \\
\hline (11) & $\chi^{d i s t} \cdot \varsigma^{\text {cons }}$ & $\begin{array}{l}.0289 * * * \\
(.0044)\end{array}$ & $\begin{array}{l}.0972^{* * * *} \\
(.0156)\end{array}$ & & & $\begin{array}{l}-.0070^{* * *} \\
(.0016)\end{array}$ & $\begin{array}{l}.4550 * * * \\
(.0601)\end{array}$ \\
\hline (12) & $\chi^{i n t} \cdot \varsigma^{\operatorname{con} s}$ & $\begin{array}{l}.0163 * * * \\
(.0042)\end{array}$ & $\begin{array}{l}.0466 * * * \\
(.0139)\end{array}$ & & & & \\
\hline (13) & $\chi^{d i s t} \cdot \varsigma^{i n v}$ & & $\begin{array}{l}.0522^{* *} \\
(.0160)\end{array}$ & $\begin{array}{l}140.0^{* * *} \\
(25.38)\end{array}$ & $\begin{array}{l}-.0099 * * * \\
(.0018)\end{array}$ & $\begin{array}{l}-.0073 * * * \\
(.0013)\end{array}$ & $\begin{array}{l}.4853^{* * *} * \\
(.0561)\end{array}$ \\
\hline (14) & $\chi^{i n t} \cdot \varsigma^{i n v}$ & & & & $\begin{array}{l}.0049^{* * *} * \\
(.0015)\end{array}$ & & $\begin{array}{l}-.7356^{* * *} \\
(.0552)\end{array}$ \\
\hline
\end{tabular}


Table 5: Regression of macroeconomic side effects

\begin{tabular}{|c|c|c|c|c|}
\hline \multicolumn{5}{|c|}{ Dependent variable } \\
\hline & Output $_{t}$ & $\#$ firms $_{t}$ & Herfindahl $_{t}$ & Unempl $l_{t}$ \\
\hline \multirow[t]{2}{*}{ Intercept } & $8.333^{* * *}$ & $64.49 * * *$ & $176.1^{* * *}$ & $7.707^{* * *}$ \\
\hline & $(.0097)$ & $(.2360)$ & $(.5364)$ & $(.0926)$ \\
\hline \multirow[t]{2}{*}{$\sigma_{t}^{\nu}$} & $-.0232^{* * *}$ & $.5106^{* * *}$ & $-1.192^{* * *}$ & $-.1335^{* * *}$ \\
\hline & $(.0013)$ & $(.0255)$ & $(.0571)$ & $(.0117)$ \\
\hline \multirow[t]{2}{*}{$\theta$} & .0067 & -.0380 & .0200 & $.1623^{*}$ \\
\hline & $(.0046)$ & $(.1628)$ & $(.3525)$ & $(.0661)$ \\
\hline \multirow[t]{2}{*}{$\varsigma^{\text {cons }}$} & -.0045 & $-.5934^{* * *}$ & $1.288^{* *}$ & .0966 \\
\hline & $(.0053)$ & $(.1801)$ & $(.4063)$ & $(.0811)$ \\
\hline \multirow[t]{2}{*}{$\varsigma^{i n v}$} & $-.0170^{* *}$ & -0.0777 & -.0995 & $.7740^{* * *}$ \\
\hline & $(.0060)$ & $(.1985)$ & $(.4506)$ & $(.0974)$ \\
\hline \multirow[t]{2}{*}{$\beta^{b}$} & -.0032 & -.1399 & .4983 & -.0670 \\
\hline & $(.0050)$ & $(.1624)$ & $(.3686)$ & $(.0736)$ \\
\hline \multirow[t]{2}{*}{$\beta^{A}$} & $-.0193^{* * *}$ & $.1828^{*}$ & $-.4089^{*}$ & $-.0822^{*}$ \\
\hline & $(.0035)$ & $(.0858)$ & $(.2052)$ & $(.0396)$ \\
\hline \multirow[t]{2}{*}{$\chi^{i n t}$} & .0026 & -0.1588 & .2881 & .1413. \\
\hline & $(.0054)$ & $(.1650)$ & $(.3549)$ & $(.0850)$ \\
\hline \multirow[t]{2}{*}{$\chi^{d i s t}$} & .0013 & -.2443 & .3788 & -.0138 \\
\hline & $(.0046)$ & $(.1613)$ & $(.3501)$ & $(.0576)$ \\
\hline$R^{2}$ & .3640 & .2778 & .2723 & .2341 \\
\hline
\end{tabular}

Signif. codes: $0^{(* * *)} 0.001^{(* *}, 0.01^{* *} 0.05$ '? $0.1^{\prime \prime}, 1$

Two-way clustered standard errors are shown in paretheses. The results are consistent across alternative panel model specifications (random effects, between).

Table 6: Initialization (policy experiment)

\begin{tabular}{|c|c|c|c|c|}
\hline & Mean (Std) & $\begin{array}{c}\text { eco } \\
\text { Mean (Std) }\end{array}$ & $\begin{array}{c}\operatorname{conv} \\
\text { Mean (Std) }\end{array}$ & $\mathrm{p}$-value \\
\hline & $.4927(.2853)$ & $.5087(.2847)$ & $4553(.2852)$ & .2346 \\
\hline$\varsigma^{i n v}$ & $.0565(.0279)$ & $.0584(.0263)$ & $.0521(.0309)$ & 2246 \\
\hline & $.0129(.0073)$ & $.0133(.0073)$ & $.0121(.0071)$ & .2788 \\
\hline$\beta^{A}$ & $.0472(.0287)$ & $.0394(.0279)$ & $.0655(.0212)$ & $6.9 \mathrm{e}-10$ \\
\hline$\beta^{b}$ & $.0524(.0280)$ & $.0488(.0276)$ & $.0609(.0272)$ & .0033 \\
\hline$\chi^{i n t}$ & $.9923(.5687)$ & $.9934(.5741)$ & $.9899(.5605)$ & .9624 \\
\hline & $.4868(.2873)$ & $.4903(.2849)$ & $.4784(.295)$ & .8429 \\
\hline
\end{tabular}

The columns show mean (standard deviation) of the initial conditions for the aggregate set of simulation runs and the subsets of green and conventional regimes. The p-value indicates whether the difference of the means across the regime subsets is significant. The parameters are drawn from the intervals: $\theta \in[0,1], \varsigma^{\text {inv }} \in[0, .1], \varsigma^{\text {cons }} \in[0, .025], \beta^{A}, \beta^{b} \in[0, .1]$, $\chi^{\text {int }}, \chi^{\text {dist }} \in[0, .5]$. 


\subsection{Figures}

Figure 1: Macroeconomic structure of Eurace@unibi-eco

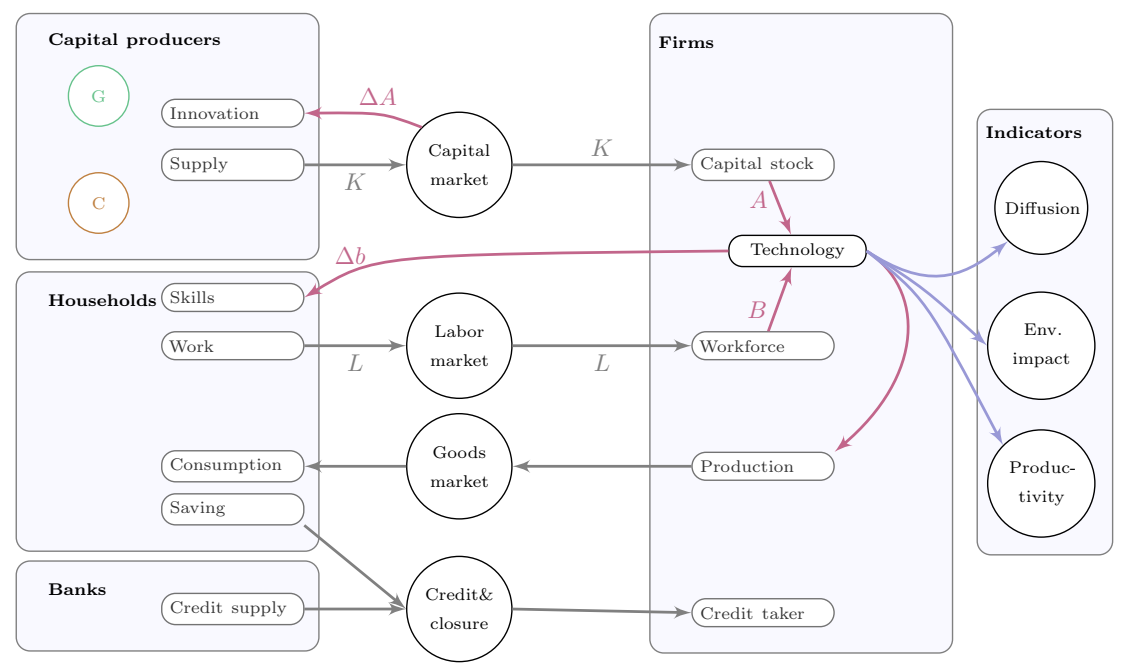

Blocks represent a group of agents and their role in the economy. Circles in the middle between show the markets as places where agents interact. Gray (magenta) arrays indicate monetary or physical (immaterial) flows. The block on the right-hand side shows the main macroeconomic indicators that have been studied. This flowchart is taken from Hötte (2019c) and based on Dawid et al. (2011).

Figure 2: Simulated pathways of transition

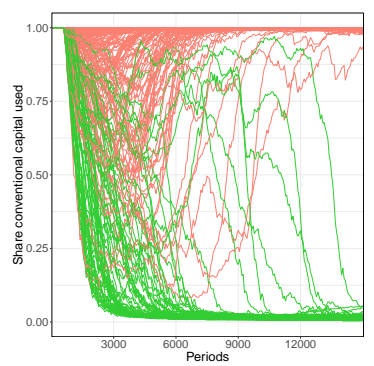

(a) $\nu_{t}^{c}$ per run

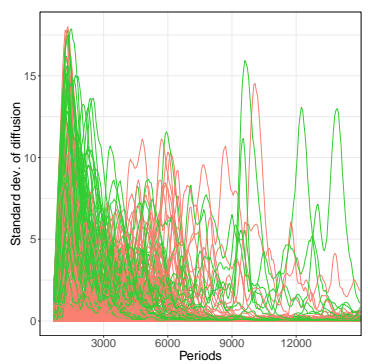

(b) $\sigma_{t}^{\nu}$ per run

These figures show the characteristics of simulated transition pathways. Each line represents a single simulation run $r$ out of a set of 210 runs. Green (red) lines indicate that the transition was (not) successful. The standard deviation $\sigma_{t}^{\nu}$ is computed over a moving time window of 2.5 years. 
Figure 3: Transition patterns in policy experiment

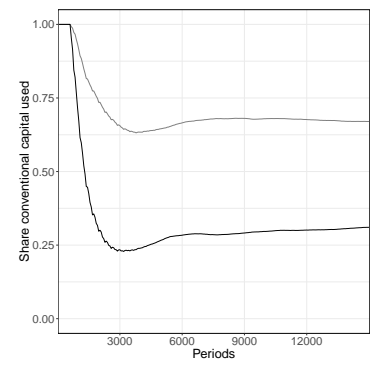

(a) Aggregate $\nu_{t}^{c}$

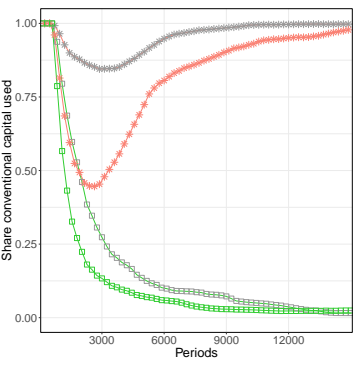

(b) $\nu_{t}^{c}$ by regime

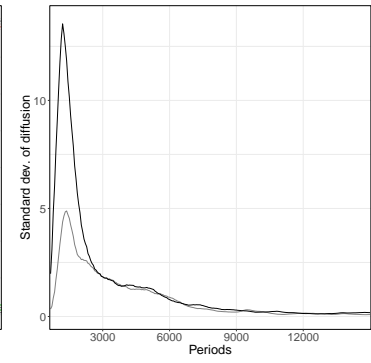

(c) Volatility $\sigma_{t}^{\nu}$

These figures show time series patterns of the diffusion curve and its volatility over time. Gray curves represent the experiment without policy. In Fig. 3b, the red (green) curve shows the aggregate diffusion curve within the subset of runs that converge to the conventional (green) regime. In Fig. 3c, $\sigma_{t}^{\nu}$ is the standard deviation of $\nu_{t}^{c}$ computed over 2.5 years.

Figure 4: Policy-induced shift in transition boundaries

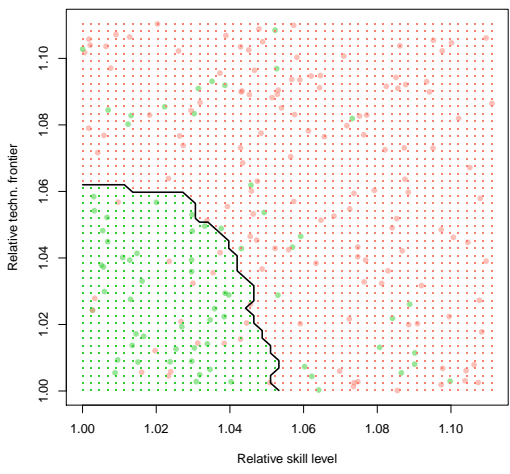

(a) No policy

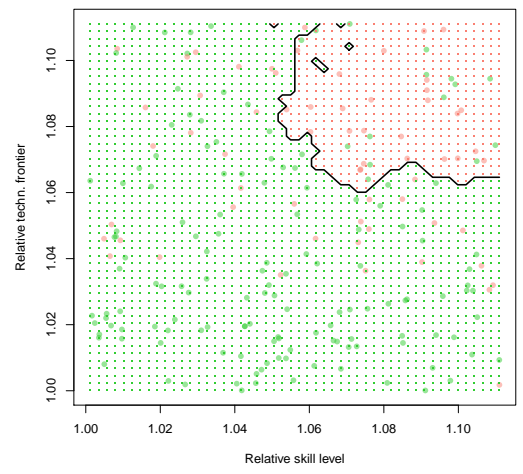

(b) Policy experiment

These figures illustrate the shift in the transition boundary. The vertical (horizontal) axis represent the relative technological frontier $\alpha_{t_{0}}=\frac{A_{t_{0}}^{c}}{A_{t_{0}}^{g}}=\frac{1}{1-\beta^{A}}$ (relative skill level $\beta_{t_{0}}=$ $\left.\frac{b_{t_{0}}^{c}}{b_{t_{0}}^{g}}=\frac{1}{1-\beta^{b}}\right)$ at the day of market entry $t_{0}$. Each dot represents a simulation run, its color indicates the resulting regime and the position the barrier combination at the day of market entry. The boundary separates green from conventional regimes. The transition boundary is derived with a k-nearest neighbors clustering algorithm that is trained to predict the regime using $\alpha_{t_{0}}$ and $\beta_{t_{0}}$ as input. Technical detail on the algorithm is available in Appendix II. 


\section{Appendix}

\section{Appendix A. Formal description of the model}

This description is an extract of the more comprehensive model documentation available in Hötte (2019b). The most relevant parts of the model are production and learning processes at the firm-level and competition on the capital goods market.

\section{Appendix A.1. Production of consumption goods}

Heterogeneous firms produce a homogeneous consumption good that is offered at firm-specific prices. Households are consumers. Their consumption decision is based on a multinomial logit function. Households' purchasing decision is probabilistic, but influenced by the price. Firms are heterogeneous by demand expectations, production efficiency and capacity. Their individual pricing and production decisions are based on a firm's estimations about future demand and conditioned on the firm's production capacity and efficiency.

The production efficiency is determined by the bundle of the productivity of the firm's physical capital stock and technology-specific skills of the firm's employees.

The productivity of physical capital is interpreted as codified knowledge. The capital stock is composed of a range of different vintages $v$ of capital that differ (possibly) by technology-type $\mathbb{1}(v)$ and productivity level $A^{v}$. Each vintage of capital is characterized by the bundle of properties $\left(\mathbb{1}(v), A^{v}\right)$ where $\mathbb{1}(v)$ is the indicator for the technology type. It takes the value 1 if the technology-type $\tau$ is conventional $c$ and zero if it is green $g$.

Employees work with capital goods in a Leontief fashion. To make effective use of the theoretical productivity $A^{v}$ of a specific vintage, employees $l$ need to know how to operate the machine. This know-how is called technology-specific skills $b_{l, t}^{\tau}$ that are acquired in a learning process. $t$ is the time index. Technologyspecific skills averaged at the firm-level $B_{i, t}^{\tau}=\frac{1}{L_{i, t}} \sum_{l \in L_{i, t}} b_{l, t}^{\tau}$ is interpreted as the firm's stock of tacit knowledge with $L_{i, t}$ as number of employees of firm $i$. The bundle of $B_{i, t}^{\tau}$ and theoretical productivity $A^{v}$ determine the firm's effective productivity $A_{i, t}^{E f f_{v}}=\min \left[A^{v}, B_{i, t}^{\tau}\right]$ for a given vintage $v$ characterized by $\left(\mathbb{1}(v), A^{v}\right)$.

Firm $i$ 's production in $t$ given by

$$
Q_{i, t}=\sum_{v=1}^{V}\left(A_{i, t}^{E f f_{v}} \cdot \min \left[K_{i, t}^{v}, \max \left[0, L_{i, t}-\sum_{k=v+1}^{V} K_{i, t}^{k}\right]\right]\right)
$$

where $\sum_{v=1}^{V} K_{i, t}^{v}$ is the firm's ordered capital stock composed of $V$ different capital stock items. The term $\max \left[0, L_{i, t}-\sum_{k=v+1}^{V} K_{i, t}^{k}\right]$ captures the fact that firms can only use as much capital as workers are available in the firm to operate the machines. Ordered capital refers to the running order of capital that is determined by the cost effectiveness of capital goods. 
Firms invest in new capital goods to replace depreciated units or to expand their production capacity. Employees are hired on the labor market.

\section{Appendix A.2. Capital goods market}

Capital goods are offered by two competing capital goods producers. Both producers are in price-per-productivity-unit competition. Each producer offers a range of different vintages that differ by productivity. Older vintages are less productive than newer vintages. Prices of capital goods are set adaptively taking account of the evolution of relative demand and profits. For example, if a producer increased prices in the previous periods and if this was associated with increasing profits the producer continues to increase prices. If profits and market share were decreasing, the producer does the opposite.

A fraction of profits is re-invested in R\&D that contributes positively to the probability of innovative success. Successful innovation shifts the frontier of the producer upward in discrete steps, i.e. $A_{\tau, t+1}^{V}=(1+\Delta A) \cdot A_{\tau, t}^{V}$. It enables the successful producer $\tau=c, g$ to bring a new and more productive vintage to the market while input requirements per produced vintage are constant. The producer can supply more productivity units using the same amount of inputs. Further detail is available in Hötte (2019b).

\section{Appendix A.3. Learning by employees}

Employees learn over time how to use capital goods efficiently. The pace of relative learning depends on $\nu_{l, t}^{\tau}=\frac{K_{l, t}^{\tau}}{K_{l, t}^{c}+K_{l, t}^{g}}$ the share of capital of type $\tau$ that is used in current production. $K_{l, t}^{\tau}$ is the amount of capital goods of type $\tau=c, g$ that is used by the firm where $l$ is working.

Technology-specific skills $b_{l, t}^{\tau}$ are updated in discrete steps. The step size $\Delta b_{l, t+1}^{\tau}=b_{l, t+1}^{\tau}-b_{l, t}^{\tau}$ is given by

$$
\Delta b_{l, t+1}^{\tau}=\chi_{l}^{g e n} \cdot\left(\left[\left(\psi_{l, t}^{\tau}\right)^{\left(1+\chi^{d i s t}\right)}\left(\psi_{l, t}^{-\tau}\right)^{\left(1-\chi^{d i s t}\right)}\right]^{1 / 2}-1\right) .
$$

The pace of learning is scaled by $l$ 's learning ability $\chi_{l}^{\text {gen }}$. Technological knowledge may be transferable across technology types and contribute to the stock of skills of the alternative technology type $-\tau$ with $\tau \neq-\tau$ and $\tau,-\tau \in\{c, g\} \cdot \chi^{\text {dist }} \in[0,1]$ is a measure for the technological distance. A smaller distance is associated with a higher degree of cross-technology transferability of skills.

$\psi_{l, t}^{\tau} \geq 1$ is the amount of knowledge learned in one period when working with technology type $\tau$. It is given by

$$
\psi_{l, t}^{\tau}=1+\left(\nu_{l, t}^{\tau}\right)^{\chi^{i n t}} \cdot \max \left[0,\left(A_{l, t}^{\tau}-b_{l, t}^{\tau}\right)\right] .
$$

It is dependent on the parameter $\chi^{\text {int }}$ which is a measure for the technological difficulty and returns to specialization. $\nu_{l, t}^{\tau}$ is a proxy for the amount of effort invested in learning by doing with capital type $\tau$. It captures the degree of technological specialization of the employer. The updating step is also dependent on the 
technical novelty $\max \left[0,\left(A_{l, t}^{\tau}-b_{l, t}^{\tau}\right)\right]$ where $A_{l, t}^{\tau}$ is the average productivity of capital goods of type $\tau$ in the employer's capital stock, i.e. $A_{l, t}^{\tau}=\frac{1}{K_{l, t}^{\tau}} \sum_{v \in K_{l, t}^{\tau}} k_{l, t}^{v}$. This reflects the potential amount of knowledge that is new to the employee. An employee can only learn if there is something new to learn. The endowment of technology-specific skills of individual employees is not observable by the firm. Firms can only estimate the average skill endowment $B_{i, t}^{\tau}$. Firms observe the amount of inputs and the amount of output. This enables the estimation of the effective productivity given by $A_{i, t}^{E f f_{v}}$. 


\section{Appendix B. Policy experiment}

[Table 6 about here.]

The entries in Table 6 show the mean (standard deviation) of the initial conditions for the full set of simulation runs and the subsets of green and conventional regimes. The last column indicates the p-value of a two-sided Wilcoxon test. Within the policy simulations, only the difference in the initial level of the barriers exhibits a significant difference when comparing the subset of green and conventional regimes. The initial policy parameters are on average slightly higher in the subset of transition regimes, but the difference is not significant using the Wilcoxon test as a test criterion.

The intervals from which the policy parameters are drawn were determined in a series of preceding analyses. Holding the other parameters fixed, the mean values of the two subsidies perform similarly well with regard to their diffusion effectiveness. The modeling framework prevents an analytical derivation of values for the instruments with equal performance. Additional discussion of this issue can be found in (Hötte, 2019c).

The intervals from which the diffusion barriers are drawn are determined such that a balanced sample of green and lock-in regimes is obtained. The levels are the same as used in the benchmark scenario introduced above I.1 and in a preceding study on the role of diffusion barriers (Hötte, 2019c).

\section{Supplementary material}

\section{Additional information on the simulation results}

\section{I.1. Barriers to diffusion and learning}

A Monte-Carlo experiment with randomly drawn levels of learning parameters $\left(\chi^{\text {dist }}, \chi^{\text {int }}\right)$ and diffusion barriers $\left(\beta^{A}, \beta^{b}\right)$ serves as benchmark scenario for the policy experiment. This baseline scenario is not a true counterfactual. Initial conditions are drawn uniformly at random from the same interval, but are not identical. However, the sample size of both experiments is supposed to be sufficiently large to draw descriptive inference.

Barriers to diffusion measured as percentage difference $\beta^{A}, \beta^{B}$ in the initial frontier $A_{g, t_{0}}^{V}=\left(1-\beta^{A}\right) \cdot A_{c, t_{0}}^{V}$ and initial endowments of employees with tacit knowledge $b_{l, t_{0}}^{g}=\left(1-\beta^{b}\right) \cdot b_{l, t_{0}}^{c}$ are drawn at random from the interval $[0, .1]$. The learning conditions are drawn from uniform intervals. The interval of $\chi^{\text {dist }} \in[0,1]$ ranges from perfect spillovers and the absence of learning spillovers. $\chi^{\text {int }} \in[0,2]$ covers the extreme cases of increasing returns to specialization $\left(\chi^{\text {int }}=2\right)$ and a pace of learning that is independent of degree of specialization at the firm level $\left(\chi^{i n t}=0\right)$. A comprehensive discussion and conceptual motivation of these parameters can be found in Hötte (2019d).

In this benchmark scenario, the transition probability accounts for $30 \%$, i.e. 70 out of 210 simulation runs converge to a green technological state. An 
overview of different macroeconomic time series plots is provided in SM I.1. In Table 2, the initial conditions of the experiment are summarized. Descriptively, it can be seen that lower diffusion barriers seem to be positively associated with the transition probability. In the subset of green regimes, initial barriers are on average lower compared to the average initial conditions in the subset of conventional regimes. A Wilcoxon test confirms that these differences are significant.

A similar observation can be made for the role of state dependence in learning. The differences across regimes are significant for the technological distance, but not for the difficulty. On average, the distance is lower in the subset of transition regimes. A longer discussion can be found in Hötte (2019d).

The transition probability, its volatility and measures for the pace and degree of technological divergence can be used to describe the pathway of transition. These indicators are introduced in Sec. 5.

A regression analysis of these indicators illustrates the relation between the relative pace of learning embodied in $\chi^{\text {dist }}$ and $\chi^{\text {int }}$ and the relative maturity of the entrant technology. The model selection procedure is described in II.

Diffusion barriers reduce the probability of a transition. A higher technological distance $\chi^{\text {dist }}$ is negatively associated with the transition probability. Further, $\chi^{\text {dist }}$ reinforces the inhibiting effect of the skill-related barrier $\beta^{b}$. A skill-related barrier is more difficult to overcome if the technological distance is high. The distance reinforces path dependence in the accumulation of tacit knowledge.

The interaction of the distance and the technical barrier $\chi^{\text {dist }} \cdot \beta^{A}$ is not clear from this analysis because the coefficients of the interaction term differ across the OLS and Probit specification. This can be explained by the different functional forms of the two models and suggests non-linearities in the relationship between the level of barriers and the degree of spillovers.

A lower initial maturity has, in general, a postponing effect on $t^{*}$. Previous analyses have shown that $\beta^{A}$ and $\beta^{b}$ are decisive for the emerging technological regime. Their effect on the diffusion volatility is ambiguous. Both, very high and very low barriers have a negative effect on $t^{*}$. Sufficiently high barriers prevent the diffusion process very early and the lock-in regime is stable. Very low barriers do not represent a burden for the entrant technology and the transition may be fast and stable. The role of barriers was more comprehensively discussed in a previous article (Hötte, 2019c).

The variance of the diffusion process $\left(\sigma_{i}^{\nu}\right)^{2}$ is generally higher if the transition occurs. The difference compared to the lock-in case is larger if barriers, the technological distance and difficulty are high.

In the regression of the measures for the relative performance $\left(\frac{A_{i}^{+}}{A_{i}^{-}}\right)^{*}$ and $\left(\frac{B_{i}^{+}}{B_{i}^{-}}\right)^{*}$, the coefficients of the knowledge barrier $\beta^{b}$ and the technological difficulty are negative in the transition regime. Hence, the divergence of relative knowledge stocks is less pronounced. This indicates that the diffusion of the green technology is more challenging in the presence of high skill-related barriers and state dependence in the learning process. 
Additional discussion about the interplay of barriers and learning parameters can be found in the description of the policy experiment in Sec. 5.2. For the sake of completeness, in Fig. I.1, some time series figure of macroeconomic core indicators are shown. A longer discussion of these simulation results can be found in (Hötte, 2019d). 
Table I.1: Pathways of transition and technology characteristics (baseline)

\begin{tabular}{|c|c|c|c|c|c|c|}
\hline & $\nu_{i}^{c}$ & $\nu_{i}^{c}$ & $t_{i}^{*}$ & $\left(\frac{A_{i}^{+}}{A_{i}^{-}}\right)^{*}$ & $\left(\frac{B_{i}^{+}}{B_{i}^{-}}\right)^{*}$ & $\left(\sigma_{i}^{\nu}\right)^{2}$ \\
\hline & OLS & Probit & IV & IV & IV & IV \\
\hline (Intercept) & $\begin{array}{c}.6599^{* * * *} \\
(.0033)\end{array}$ & $\begin{array}{l}.8293^{* * *} \\
(.0203)\end{array}$ & $\begin{array}{c}3519 * * * \\
(183.3)\end{array}$ & $\begin{array}{c}1.112^{* * *} \\
(.0178)\end{array}$ & $\begin{array}{l}1.07 * * * \\
(.0138)\end{array}$ & $\begin{array}{c}2.569^{* * *} \\
(.3278)\end{array}$ \\
\hline$\chi^{\text {dist }}$ & $\begin{array}{c}.0934 * * * \\
(.0037)\end{array}$ & $\begin{array}{c}.6556 * * * \\
(.0238)\end{array}$ & $\begin{array}{c}1220 * * * \\
(120.5)\end{array}$ & $\begin{array}{l}.075^{* * *} * \\
(.0106)\end{array}$ & $\begin{array}{c}.0955 * * * \\
(.0079)\end{array}$ & $\begin{array}{c}-.698 * * * \\
(.1326)\end{array}$ \\
\hline$\chi^{i n t}$ & $\begin{array}{l}-.0027 \\
(.0034)\end{array}$ & -.028. & $\begin{array}{c}492.9 * * * \\
(110.1)\end{array}$ & $\begin{array}{l}.0176^{*} \\
(.0087)\end{array}$ & $\begin{array}{l}.0086 \\
(.0063)\end{array}$ & $\begin{array}{c}-.4932^{* * * *} \\
(.1009)\end{array}$ \\
\hline$\chi^{d i s t} \cdot \chi^{i n t}$ & & & & & & $\begin{array}{c}-.8477 * * * \\
(.0493)\end{array}$ \\
\hline$\beta^{A}$ & $\begin{array}{l}.1532 * * * \\
(.0038)\end{array}$ & $\begin{array}{c}.7162 * * * \\
(.0218)\end{array}$ & $\begin{array}{c}1168 * * * \\
(111.3)\end{array}$ & $\begin{array}{c}.0487 * * * \\
(.0057)\end{array}$ & $\begin{array}{c}.0437 * * * \\
(.0056)\end{array}$ & $\begin{array}{c}-.454 * * \\
(.1491)\end{array}$ \\
\hline$\beta^{b}$ & $\begin{array}{c}.1871^{* * * *} \\
(.0034)\end{array}$ & $\begin{array}{c}.8811 * * * \\
(.0194)\end{array}$ & $\begin{array}{c}368.6 * * * \\
(81.76)\end{array}$ & $\begin{array}{c}.0987 * * * \\
(.0091)\end{array}$ & $\begin{array}{c}.0915 * * * \\
(.007)\end{array}$ & $\begin{array}{c}-1.654^{* * * *} \\
(.1448)\end{array}$ \\
\hline$\chi^{d i s t} \cdot \beta^{A}$ & $\begin{array}{c}-.0209 * * * \\
(.0034)\end{array}$ & $\begin{array}{c}.1041 * * * \\
(.016)\end{array}$ & & $\begin{array}{l}.0221 * * * \\
(.0046)\end{array}$ & $\begin{array}{c}.0155 * * * \\
(.0033)\end{array}$ & \\
\hline$\chi^{\text {dist }} \cdot \beta^{b}$ & $\begin{array}{c}.0328^{* * *} * \\
(.0033)\end{array}$ & $\begin{array}{c}.4102^{* * *} * \\
(.0191)\end{array}$ & & $\begin{array}{c}.0311 * * * \\
(.0082)\end{array}$ & $\begin{array}{c}.0222 * * * \\
(.0062)\end{array}$ & $\begin{array}{l}-.0574 \\
(.0872)\end{array}$ \\
\hline$\chi^{i n t} \cdot \beta^{A}$ & $\begin{array}{c}-.0542 * * * \\
(.0033)\end{array}$ & $\begin{array}{c}-.1541 * * * \\
(.0141)\end{array}$ & & & & $\begin{array}{l}.1126 \\
(.0747)\end{array}$ \\
\hline$\chi^{i n t} \cdot \beta^{b}$ & & & $\begin{array}{c}-305.5^{* * *} \\
(44.51)\end{array}$ & $\begin{array}{c}-.0109 * * * \\
(.0032)\end{array}$ & $\begin{array}{c}-.0069 * * \\
(.0023)\end{array}$ & \\
\hline $\mathbb{1}(e c o)$ & & & $\begin{array}{l}-699.8 \\
(449.1)\end{array}$ & $\begin{array}{l}-.1107^{*} \\
(.0497)\end{array}$ & $\begin{array}{l}-.0499 \\
(.0384)\end{array}$ & $\begin{array}{c}9.839^{* * * *} \\
(.889)\end{array}$ \\
\hline $\mathbb{1}(e c o) \cdot \chi^{d i s t}$ & & & $\begin{array}{c}-2428^{* * *} \\
(198.4)\end{array}$ & $\begin{array}{l}-.0541 . \\
(.0282)\end{array}$ & $\begin{array}{c}-.0974 * * * \\
(.0209)\end{array}$ & $\begin{array}{c}1.203^{* * *} * \\
(.3091)\end{array}$ \\
\hline $\mathbb{1}(e c o) \cdot \chi^{\text {int }}$ & & & $\begin{array}{c}-1305 * * * \\
(236.1)\end{array}$ & $\begin{array}{c}-.0579 * * \\
(.0188)\end{array}$ & $\begin{array}{c}-.0295^{*} \\
(.0134)\end{array}$ & $\begin{array}{c}2.158^{* * * *} \\
(.2425)\end{array}$ \\
\hline $\mathbb{1}(e c o) \cdot \beta^{A}$ & & & $\begin{array}{c}-929.1 * * * \\
(198.5)\end{array}$ & & & $\begin{array}{l}-.4974 \\
(.2705)\end{array}$ \\
\hline $\mathbb{1}(e c o) \cdot \beta^{b}$ & & & & $\begin{array}{c}-.1210^{* * * *} \\
(.0111)\end{array}$ & $\begin{array}{c}-.1156 * * * \\
(.0075)\end{array}$ & $\begin{array}{c}3.997^{* * *} \\
(.2980)\end{array}$ \\
\hline$A_{c}^{V}$ & & $\begin{array}{c}.1455 * * * \\
(.0232)\end{array}$ & & $\begin{array}{c}.0171^{* * *} \\
(.0020)\end{array}$ & $\begin{array}{c}.0225^{* * *} * \\
(.0031)\end{array}$ & $\begin{array}{c}-.3407 * * * \\
(.0789)\end{array}$ \\
\hline$B_{i}^{c}$ & & & $\begin{array}{c}-151.4^{* * *} \\
(31.66)\end{array}$ & $\begin{array}{c}-.0061 * * * \\
(.0018)\end{array}$ & $\begin{array}{c}-.0054 * * * \\
(.0013)\end{array}$ & \\
\hline \#employees $_{i}$ & & & $\begin{array}{c}-263.7 * * * \\
(31.96)\end{array}$ & $\begin{array}{c}-.0111 * * * \\
(.0022)\end{array}$ & $\begin{array}{c}-.0097 * * * \\
(.0024)\end{array}$ & \\
\hline output $_{i}$ & $\begin{array}{c}.0159 * * * \\
(.0046)\end{array}$ & & & & & \\
\hline price $_{i}$ & $\begin{array}{c}.0251^{* * * *} \\
(.0047)\end{array}$ & $\begin{array}{l}.049 * * * \\
(.0142)\end{array}$ & & & $\begin{array}{c}-.0039 * \\
(.0018)\end{array}$ & $\begin{array}{l}.0682 \\
(.0418)\end{array}$ \\
\hline \#firms & $\begin{array}{c}-.0105 * * \\
(.0033)\end{array}$ & & & & & $\begin{array}{c}-.3611^{* * *} * \\
(.0429)\end{array}$ \\
\hline$p^{e c o} / w^{r}$ & $\begin{array}{c}-.0167^{* * *} * \\
(.0043)\end{array}$ & $\begin{array}{c}.1000^{* * *} * \\
(.0294)\end{array}$ & & & $\begin{array}{c}.0149 * * * \\
(.0035)\end{array}$ & $\begin{array}{c}-.3424 * * * \\
(.0919)\end{array}$ \\
\hline$R^{2}$ & .3417 & .4952 & .1626 & .3436 & .4168 & .2759 \\
\hline
\end{tabular}

The first two columns show the diffusion measure $\nu_{i}^{c}$ evaluated at the end of simulation. The third column illustrates the relationship between initial conditions and the duration $t^{*}$ until the diffusion process stabilizes. $\left(\frac{A_{i}^{+}}{A_{i}^{-}}\right)^{*}\left(\left(\frac{B_{i}^{+}}{B_{i}^{-}}\right)^{*}\right)$ are measures for the relative stock of codified (tacit) knowledge at firm-level in time $t_{i}^{*}$. The variance $\left(\sigma_{i}^{\nu}\right)^{2}$ is a measure for the volatility of the diffusion process. The results in column 3-6 are the results of an instrumental variable regression taking account of the potential endogeneity of the type dummy $\mathbb{1}(e c o)$. Further info is available Sec. II. 
Figure I.1: Macroeconomic and technological indicators (baseline)

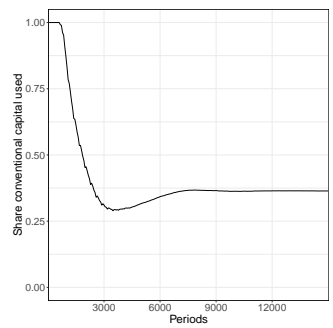

(a) $\nu_{t}^{c}$ batch

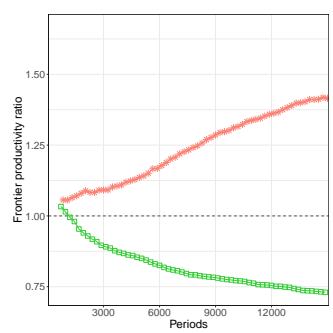

(d) $\alpha_{t}=\frac{A_{c, t}^{V}}{A_{g, t}^{V}}$

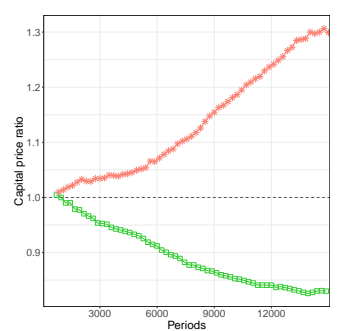

(g) $\frac{p_{t}^{c}}{p_{t}^{g}}$

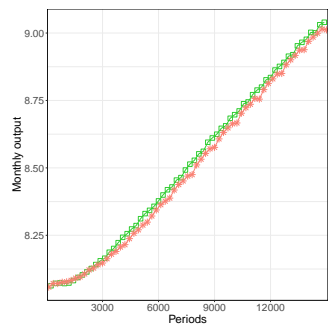

(j) Monthly output

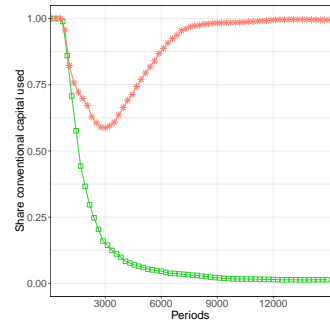

(b) $\nu_{t}^{c}$ by regime type

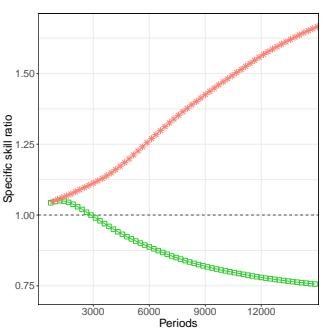

(e) $\beta_{t}=\frac{b_{t}^{c}}{b_{t}^{g}}$

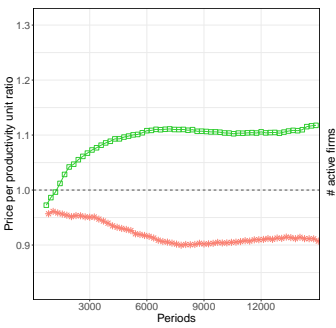

(h) $\frac{p_{t}^{c} / A_{t}^{c}}{p_{t}^{g} / A_{t}^{g}}$

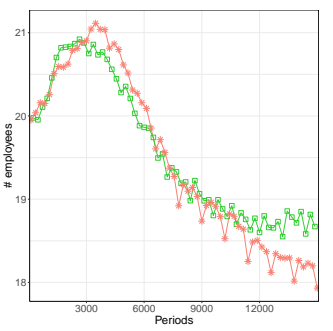

(k) Avg. \# employees per firm

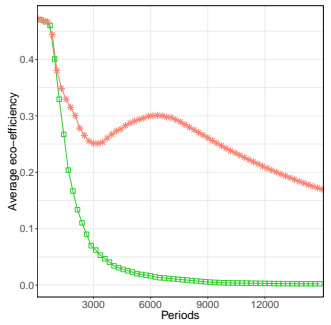

(c) Eco-efficiency

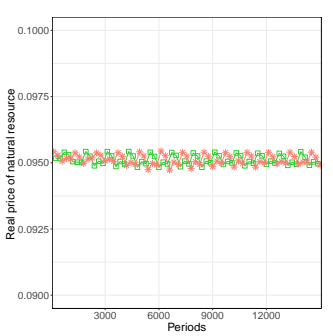

(f) $\frac{p_{t}^{e c o}}{w_{t}^{T}}$

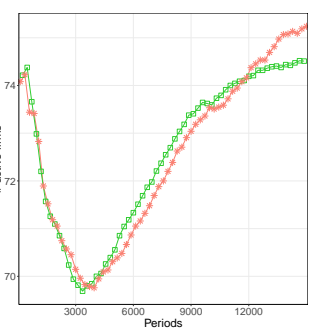

(i) \# active firms

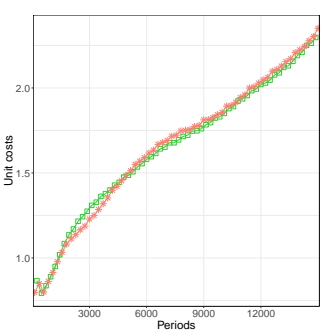

(1) Unit costs 


\section{I.2. Additional information about the macroeconomic evolution in the policy experiment}

In this section, some additional information about the macroeconomic and technological side effects of policy are illustrated by time series plots and briefly explained. In figures I.2a to I.2e the evolution of technological indicators is shown comparing the aggregate outcome of the policy simulations with the baseline. The difference in the subset of conventional regimes between the policy and business as usual case is remarkable. In the early simulation phase, policies trigger a higher green technology uptake, independently of the resulting regime. This has positive effects on the environmental performance in the short run. The environmental impact per output unit ("eco-efficiency") is lower in the beginning, but not necessarily in the long run. If the economy is locked in and does not switch to the green regime, eco-policies cause a distortion in the allocation of learning and $R \& D$ resources. The specialization in the conventional technology is retarded which has a negative effect on productivity compared to the baseline scenario without policy. This is also visible in the evolution of relative knowledge stocks $\alpha_{t}$ and $\beta_{t}$.

In Fig. I.2f the budget balance measured as percentage GDP is shown. It fluctuates around zero which confirms that the budget is balanced on average. The fluctuations are largest for the green transition regimes in the policy scenario. This is largely explainable by the pro-cyclical behavior of the subsidy payments which are correlated with sold quantity of green goods and investment dynamics in green capital. If green capital is not adopted, subsidies are not paid. Figure I. $2 \mathrm{~g}$ illustrates the functioning of the budget balancing mechanism. The base income tax is incrementally adapted such that the budget is balanced in the long run. It is not only responsive to the expenditures and income of green policies, but also to the payment of unemployment benefits, corporate tax rates and government's involvement in the financial sector, i.e. via the government's interest income and payment.

The day of market entry causes severe distortions in the economic system. It is associated with increased competition and a series of market exits independent of the resulting technological regime and independent of the policy as shown in Fig. I.2h. The series of market exits is associated with a growth of the firm size. Note that the market entry dynamics in this model are highly stylized and probabilistic. Only the survival rate of entrants and the number of exits is endogenous and responsive to the technological evolution and policies.

In the policy scenario, the distortions are stronger and seem to be a side effect of relatively higher green technology adoption rates. This is partly reflected in monthly output with a short phase of stagnation that can be explained by learning costs incurred in the beginning. Recall that also in the lock-in regimes, inefficiencies arise because some firms take up the green technology. This is observable in the rise of unit costs in figure I.2l. Unit costs steeply increase immediately after the day of market entry.

The simulations in the model tend to exhibit "technological unemployment" that is not compensated by consumption growth. If productivity grows, firms 
Figure I.2: Macroeconomic and technological indicators (experiment)

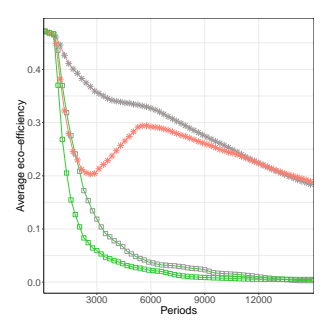

(a) Eco-efficiency

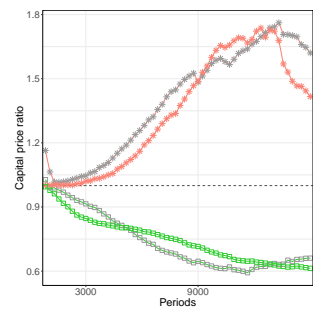

(d) $\frac{p_{t}^{c}}{p_{t}^{g}}$

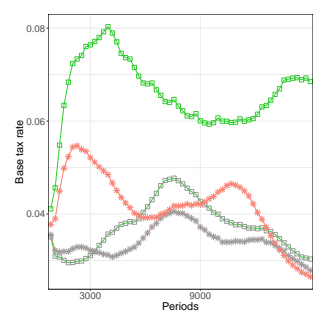

(g) Base tax

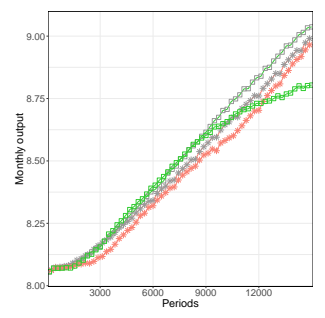

(j) Monthly output

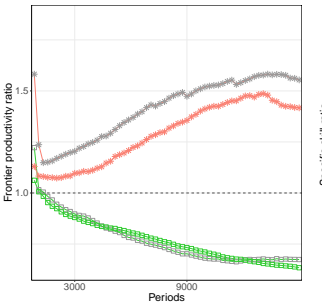

(b) $\alpha_{t}=\frac{A_{c, t}^{V}}{A_{g, t}^{V}}$

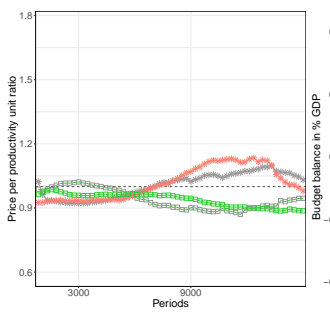

(e) $\frac{p_{t}^{c} / A_{t}^{c}}{p_{t}^{g} / A_{t}^{g}}$

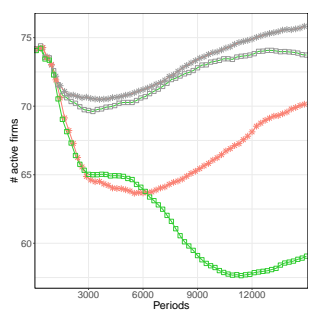

(h) \# active firms

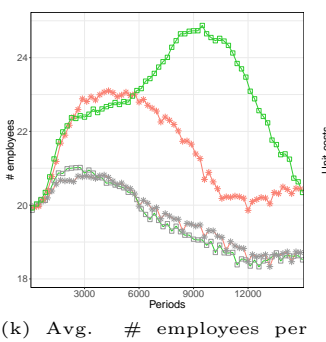

(k) $A$
firm

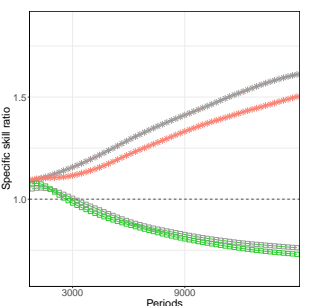

(c) $\beta_{t}=\frac{b_{t}^{c}}{b_{t}^{g}}$

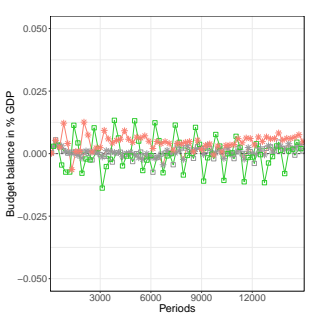

(f) Budget balance (\%GDP)

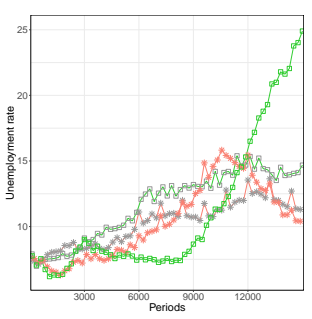

(i) Unemployment rate

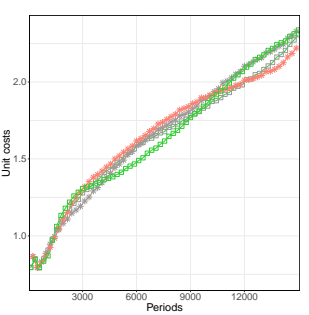

(1) Unit costs

These figures give an overview of the time seriesof macroeconomic and technological indicators. The different line shapes indicate different regime types ( $\square$ : eco, *: conv). Gray colored lines indicate the baseline scenario. 
dismiss labor, but the dismissal rates are low. In the baseline case, the unemployment rate increases over a horizon of roughly 60 yeas from 5 to $12.5 \%$. In the presence of policy, this behavior is different and largely explainable by the consumption subsidy. The consumption subsidy makes green consumption goods cheaper. Hence, it is only paid if green technology is used. In the case green policy regimes, this price support is sufficient to stimulate demand such that the tendency of "technological unemployment" is overcome. But this effect is not permanent and conditional on the subsidy.

Recall that all the phenomena discussed here apply to Monte-Carlo simulations with different levels of initial barriers, learning parameters and policy strength that are independently drawn at random from continuous intervals. Dependent on these conditions, the dynamics may be more extreme or modest. The discussion above refers to the average outcome, but preceding simulations and experiments have shown that these patterns are quite robust and, even if no guarantee can be given, this simple method of scenario aggregation seems eligible for the given parameter ranges. 


\section{I.2.1. Monte-Carlo regression analysis}

Table I.2: Pathways of transition and technology characteristics (full)

\begin{tabular}{|c|c|c|c|c|c|c|}
\hline & $\begin{array}{c}\nu_{i}^{c} \\
\text { OLS }\end{array}$ & $\begin{array}{c}\nu_{i}^{C} \\
\text { Probit } \\
\end{array}$ & $\begin{array}{l}t_{i}^{*} \\
\mathrm{IV} \\
\end{array}$ & $\begin{array}{c}\left(\frac{A_{i}^{+}}{A_{i}^{-}}\right)^{*} \\
\mathrm{IV}\end{array}$ & $\begin{array}{c}\left(\frac{B_{i}^{+}}{B_{i}^{-}}\right)^{*} \\
I_{V}\end{array}$ & $\begin{array}{c}\left(\sigma_{i}^{\nu}\right)^{2} \\
\text { IV }\end{array}$ \\
\hline (Intercept) & $\begin{array}{c}.3381^{* * * *} \\
(.0043)\end{array}$ & $\begin{array}{l}.4684^{* * * * *} \\
(.0144)\end{array}$ & $\begin{array}{c}3794^{* * *} \\
(70.63)\end{array}$ & $\begin{array}{c}1.099^{* * * *} \\
(.0031)\end{array}$ & $\begin{array}{c}1.097^{* * * *} \\
(.0029)\end{array}$ & $\begin{array}{c}6.548 * * * \\
(.1399)\end{array}$ \\
\hline$\chi^{\text {dist }}$ & $\begin{array}{l}-.013^{* *} \\
-(0044)\end{array}$ & $-.0898^{* * * *}$ & $\begin{array}{l}-471 * * * \\
(65.99)\end{array}$ & $\begin{array}{l}.0141 * * * * \\
.0041)\end{array}$ & $\begin{array}{c}.0213 * * * \\
(0031)\end{array}$ & $\begin{array}{l}-.9603 * * * * \\
-(1172)\end{array}$ \\
\hline$\chi^{i n t}$ & $\begin{array}{l}.0081 \\
(.0043)\end{array}$ & $\begin{array}{l}-.0161 \\
(.0145)\end{array}$ & $\begin{array}{c}-117.2^{* * *} \\
(31.42)\end{array}$ & $\begin{array}{l}.0085 * * * \\
.0017)\end{array}$ & $\begin{array}{c}.0078 * * * * \\
(0012)\end{array}$ & $\begin{array}{l}-.024 \\
(.0535)\end{array}$ \\
\hline$\chi^{d i s t} \cdot \chi^{i n t}$ & $\begin{array}{l}-.0291 * * * \\
(0045)\end{array}$ & $-.0701 * * *$ & & & & \\
\hline$\theta$ & $\begin{array}{l}-.03^{* * * *} \\
-(0043)\end{array}$ & $\begin{array}{l}.1119 * * * \\
-.1119 * 7\end{array}$ & $788.9 * * *$ & $-.0297 * * *$ & $-.0296 * * *$ & $2.267 * * *$ \\
\hline$\varsigma^{\text {cons }}$ & $\begin{array}{l}-.00401 * * * * \\
-(.0044)\end{array}$ & $\begin{array}{c}.173 * * * \\
-(.0151) \\
(.0151)\end{array}$ & 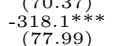 & $\begin{array}{l}.0085 * * * \\
.0018)\end{array}$ & $\begin{array}{r}.0029) \\
-.0065 * \\
(0032)\end{array}$ & $\begin{array}{l}-.1806 * * * * \\
-(0536)\end{array}$ \\
\hline$\varsigma^{i n v}$ & $\begin{array}{l}-.0205 * * * \\
-.02045)\end{array}$ & $-.0763^{* * *}$ & $-310.8^{* * *}$ & $\begin{array}{l}-.0010) * 369 * * * \\
-.03637)\end{array}$ & $\begin{array}{l}-.028627 * * * \\
-.023)\end{array}$ & $1.506 * * *$ \\
\hline$\beta^{A}$ & $.1139 * * *$ & $.465 * * *$ & $\begin{array}{l}8.747 \\
(27.75)\end{array}$ & $\begin{array}{l}.0395 * * * * \\
(0049)\end{array}$ & $.0069 * * * *$ & $-.3212 * * *$ \\
\hline$\beta^{b}$ & $.0946 * * *$ & $.2974^{* * * *}$ & $-501 * * *$ & $.0478 * * *$ & $.0519^{* * * *}$ & $\begin{array}{l}(.0894 * * * \\
-2.894 * *\end{array}$ \\
\hline$\chi^{\text {dist }} \cdot \theta$ & $\begin{array}{l}(.0044) \\
-.0504 * * * \\
\end{array}$ & $-.1177^{* * *}$ & $-119.3^{* * *}$ & $-.0111 * * *$ & $\begin{array}{l}-.00635 * * * \\
-.00611)\end{array}$ & $\begin{array}{l}(.1436) \\
.4541^{* * * *}\end{array}$ \\
\hline$\chi^{i n t} \cdot \theta$ & $\begin{array}{l}(.0044) \\
.046 * * *\end{array}$ & $\begin{array}{c}(.0149) \\
.1706^{* * *}\end{array}$ & $\begin{array}{c}(28.46) \\
-143.2^{* * * *}\end{array}$ & & $(.0014)$ & $(.0609)$ \\
\hline$\chi^{d i s t} \cdot{ }_{\varsigma}^{c o n s}$ & $\begin{array}{l}.0289 * * * * \\
(.0044)\end{array}$ & $\begin{array}{c}.0912 * * * * \\
(.0156)\end{array}$ & & & $\begin{array}{l}-.0070 * * * * \\
-.0016)\end{array}$ & $\begin{array}{l}.4550 * * * \\
(.0601)\end{array}$ \\
\hline$\chi^{i n t} \cdot \varsigma^{c o n s}$ & $\begin{array}{l}.0163^{* * * *} \\
(.0042)\end{array}$ & $\begin{array}{c}.046 * * * * \\
.0139)\end{array}$ & & & & \\
\hline$\chi^{\text {dist }} \cdot \varsigma^{i n v}$ & & $\begin{array}{l}.0522 * * \\
(.016)\end{array}$ & $\begin{array}{l}140 * * * \\
(25.38)\end{array}$ & $\begin{array}{c}-.0099 * * * * \\
(.0018)\end{array}$ & $\begin{array}{c}-.0073 * * * \\
(.0013)\end{array}$ & $\begin{array}{c}.4853 * * * \\
(.0561)\end{array}$ \\
\hline$\chi^{i n t} \cdot \varsigma^{i n v}$ & & & & $\begin{array}{c}.0049 * * * \\
(.0015)\end{array}$ & & $\begin{array}{l}-.7356 * * * * \\
-(.0552)\end{array}$ \\
\hline$\chi^{d i s t} \cdot \beta^{A}$ & $\begin{array}{l}-.0378^{* * * *} \\
(.0044)\end{array}$ & $\begin{array}{c}-.1738 * * * \\
(.0199)\end{array}$ & $\underset{(23.1)}{195.1 * * *}$ & & & $\begin{array}{c}.5285 * * * \\
(.0442)\end{array}$ \\
\hline$\chi^{d i s t} \cdot \beta^{b}$ & $\begin{array}{l}.0447 * * * \\
(0046)\end{array}$ & $\begin{array}{l}.1624^{* * * *} \\
(0163)\end{array}$ & $301.8^{* * * *}$ & & $.0092 * * * *$ & $.2984 * * *$ \\
\hline$\chi^{i n t} \cdot \beta^{A}$ & $\begin{array}{l}(.0046) \\
-.0171 * * * \\
(0044)\end{array}$ & $\begin{array}{r}(.0163) \\
-.1635 * * * \\
(0199)\end{array}$ & & & & \\
\hline$\chi^{i n t} \cdot \beta^{b}$ & $\begin{array}{l}.0301 * 1 * * * \\
.0044)\end{array}$ & $\begin{array}{c}.0975 * * * \\
(.0149)\end{array}$ & & & & $\begin{array}{l}-.2552 * * * * \\
(.0485)\end{array}$ \\
\hline $\mathbb{1}(e c o)$ & & & $\begin{array}{c}-2718 * * * \\
(144.4)\end{array}$ & $\begin{array}{l}-.1695 \% * * * \\
(.0071)\end{array}$ & $\begin{array}{l}-.1753^{* * * *} \\
(.0061)\end{array}$ & $\begin{array}{l}2.874 * * * \\
(.324)\end{array}$ \\
\hline $\mathbb{1}(e c o) \cdot \chi^{\text {dist }}$ & & & $1144 * * *$ & $-.0222^{*}$ & $-.0213 * * *$ & $2.658 * * *$ \\
\hline $\mathbb{1}(e c o) \cdot \theta$ & & & $\begin{array}{l}\text { 1070**** } \\
-1070 * * 2\end{array}$ & $.054^{* * * * *}$ & $\begin{array}{l}.05062 * * * \\
.0532 * 0 *\end{array}$ & $\begin{array}{l}-3.9619 * * * * \\
-3.900 *\end{array}$ \\
\hline $\mathbb{1}(e c o) \cdot \varsigma^{\text {cons }}$ & & & $\begin{array}{c}671.4^{* * *} \\
(149.1)\end{array}$ & & $\begin{array}{l}.0239 * 1 * * \\
.0066) \\
(.0066)\end{array}$ & \\
\hline $\mathbb{1}(e c o) \cdot \varsigma^{i n v}$ & & & $843.7^{* * * *}$ & $.0952 * * *$ & $.0772 * * *$ & $-2.392 * * *$ \\
\hline $\mathbb{1}(e c o) \cdot \beta^{A}$ & & & & $\begin{array}{l}-.0413 * * * * \\
-.006)\end{array}$ & & \\
\hline $\mathbb{1}(e c o) \cdot \beta^{b}$ & & & $\begin{array}{c}786.3^{* * *} \\
(137.2)\end{array}$ & $\begin{array}{l}-.0908 * * * * \\
-(.0084)\end{array}$ & $\begin{array}{l}-.1064 * * * \\
(.0074)\end{array}$ & $\begin{array}{l}4.706 * * * \\
(.31)\end{array}$ \\
\hline$A_{c}^{V}$ & $\begin{array}{l}-.017 * * * \\
(0044)\end{array}$ & & $102.9^{* * *}$ & $\begin{array}{l}.0066^{* * * *} \\
(0018)\end{array}$ & $\begin{array}{l}.0072^{* * * *} \\
(0012)\end{array}$ & $\begin{array}{l}-.2764 * * * \\
(0548)\end{array}$ \\
\hline$B_{i}^{c}$ & & & & & & $.2179^{* * * *}$ \\
\hline \#employees $_{i}$ & $-.143^{* * * *}$ & $-.4386^{* * *}$ & & & & $.3848 * * *$ \\
\hline output $_{i}$ & $\begin{array}{l}. .0257) * \\
.1674^{* * *}\end{array}$ & $.5116^{* * * *}$ & & & & \\
\hline price $_{i}$ & $\begin{array}{l}(.0259) \\
.0254 * * * \\
.0057)\end{array}$ & $\begin{array}{l}(.0886) \\
.0634^{* * * *}\end{array}$ & & & & \\
\hline \#firms & $\begin{array}{l}.0272 * * * \\
(.0043)\end{array}$ & $\begin{array}{l}.0988^{* * * *} \\
(.0142)\end{array}$ & $\begin{array}{c}-120 * * * \\
(25)\end{array}$ & & $\begin{array}{l}-.0035^{* * * *} \\
(8 \mathrm{e}-04)\end{array}$ & \\
\hline$R^{2}$ & .1868 & $\begin{array}{l}.266 \\
\end{array}$ & .2071 & .2483 & .2699 & .315 \\
\hline
\end{tabular}

In this table, the coefficients of the full regression models on firm-level data are shown. Additional detail on the specification of the regression equations is provided in the main article and appendix. 


\section{Technical notes on the statistical procedures}

Relationship between aggregate growth and the transition stability. In Sec. 5, the negative relationship between aggregate growth and the diffusion volatility is mentioned. This finding is robust across different model specifications and levels of aggregation.

It was evaluated at an aggregate and at the run-specific level. At the aggregate level, it the correlation between the aggregate volatility computed as variance $\left(\sigma_{T}^{\nu}\right)^{2}$ of $\nu_{t}^{c}$ across the whole simulation horizon and the average growth rate within a single simulation run. The correlation between both measures is negative and a simple regression analysis including a type-dummy confirms the significance of this relationship.

At the run-specific level, this relationship is investigated through a series of panel data methods. The data is indexed by time and run identity. I tested an fixed effects, a between, a first differences (FD) and a random effects estimator. The results of the between and FD estimator are not significant. The other estimators confirm the negative relationship at a $<0.1 \%$ level. Likely, the FD estimator is not significant due to the data types that are used. The variance is computed as running average across a 2.5 year window and the variation between individual two time steps is small. The results mentioned in the text are the estimates of a pooled regression analysis using two-way clustered standard errors on run-time.

This relationship was confirmed and more comprehensively discussed in previous studies within slightly different settings (cf. Hötte, 2019c,b,d). The volatility of the diffusion measure is dependent on the conditions of technological learning and the strength of initial diffusion barriers. Both are drawn at random in this example and are fixed within a single simulation run. A more comprehensive discussion of the relationship between these properties and the transition stability can be found in Hötte (2019d).

Data. The data used in the regression in Table 4 is one year average smoothed data. Observations are monthly snapshots captured at different iterations representing initial conditions and the final state. The intervals used for smoothing range from $[600,820]$ and $[14780,15000]$ and cover 12 monthly snapshots. One month consists of $t=20$ iterations interpreted as working days.

The set of firms used for the regression analysis shown in Table I.1 is truncated. The data of firms exhibits the structure of an unbalanced panel with entries and exits. The diffusion volatility is only meaningful if the full life time of a firm is considered. Here, only firms are considered that survive during the whole simulation horizon. For other dependent variables, the lack of completeness is ignored.

Explanatory variables. Conceptually, it is distinguished between explanatory variables and controls. Explanatory variables capture the properties of competing technologies. Controls are not of major interest, but control for differences between different simulation runs and differences between firms. 
Core explanatory variables are interactive properties $\chi^{\text {int }}$ and distance $\chi^{\text {dist }}$, initial relative maturity of the entrant $\beta^{A}, \beta^{B}$ and policy instruments $\theta$, $\varsigma^{i n v}$ and $\varsigma^{\text {cons }}$. Policy instruments can be alternatively interpreted as features of the socio-technical landscape (see 5.3).

These variables are included as identities, squared and interaction terms. The procedure to select relevant terms is explained below.

In some analyses, a dummy variable $\mathbb{1}(e c o)$ is included to control for systematic differences across the two technological regimes. It is included as identity capturing fix differences in the intercept and as interaction term with explanatory variables to capture differences in the slope of explanatory variables.

Explanatory variables and controls are normalized to obtain quantitatively comparable coefficients. The data were demeaned and scaled by division by the standard deviation. Normalization was made using the R-function scale() (R Core Team, 2018). This facilitates the comparison of coefficients with some limitations that are due to the design of the experiment.

With some limitations, quantitative inference about the effectiveness can be drawn. For example, in Table 4 the effect of the $\varsigma^{\text {cons }}$ on $\nu_{i, T}^{c}$ is quantitatively the strongest when neglecting the interaction effects. If interactions with diffusion barriers and learning parameters are absent, an increase of $\varsigma^{\text {cons }}\left(\theta\right.$, $\left.\varsigma^{i n v}\right)$ is associated with a $4(3,2) \%$ higher transition probability (column (1)). All explanatory variables were scaled and normalized to allow a comparison of coefficients. But the size of the intervals from which the parameters are drawn is not entirely comparable because of the non-linear effects of interaction terms. A longer discussion is available in the technical appendix of Hötte (2019d).

Micro- and macroeconomic control variables. The macroeconomic controls included in the regression analyses at the macroeconomic level are the aggregate stock of codified $A_{c}^{V}$ in $t_{0}$ and the number of active firms as proxy for the competitive environment. $A_{c}^{V}$ does not measure the difference in knowledge stocks, but captures technological progress in general that occurred until the day of market entry. Note that the differences in the levels of macroeconomic indicators capture differences between simulation runs that arose until $t_{0}=600$.

Firm-level microeconomic controls are firm-level stocks of tacit knowledge $B_{i}^{c}$, the number of employees and output as proxies for firm size and the firm's price. $B_{i}^{c}$ is a proxy for the firm's productivity and the price might be an indicator for the firm's future market performance and investment behavior. This is discussed in more detail in Hötte (2019c).

Dependent variables. The share of conventional capital $\nu_{i, T}^{c}$ can be directly measured. Its rounded value is used in the Probit model.

The time until technological stabilization $t_{i}^{*}$ is defined as the last local extremum in the smoothed diffusion curve measured by $\nu_{i, t}^{c}$. It is the last change in the direction of the firm-level adoption behavior within a single simulation run. After $t_{i}^{*}$, firm $i$ does not any longer switch between green and conventional capital. At the macroeconomic level, the economy starts converging to one of the two possible technological states. Due to the possibly non-smooth behavior 
of the depreciation function at the firm-level, one-year average data of $\nu_{i, t}^{c}$ is used to identify $t_{i}^{*}$.

Technological indicators evaluated at $t_{i}^{*}$ are interpreted as threshold levels in the relative performance. These are measures for degree of technological divergence beyond which the direction of technological change is trivial. The degree of divergence is measured by the ratio of productivity $\alpha_{i}^{*}=\left(\frac{A_{i, t^{*}}^{+}}{A_{i, t^{*}}^{-}}\right)$and skills $\beta_{i}^{*}=\left(\frac{B_{i, t^{*}}^{c}}{B_{i, t^{*}}^{-}}\right)$comparing the superior + with the inferior - technology. Superior is defined as the "winner" of the technology race. If the green (conventional) technology dominates in $T$, the green (conventional) technology is said to be the winner.

The data set used for the analyses of performance thresholds and the stabilization time $t_{i}^{*}$ is truncated. In particular, all observations are removed in which $t_{i}^{*}$ corresponds to the last or first observation. If $t_{i}^{*}$ coincides with the day of market entry, the diffusion pattern is trivial because the technological trajectory is clear from the beginning. The green technology does (not) diffuse without any competitive race among the two technology types. This may occur if barriers are prohibitively high that diffusion is prevented or such low that diffusion is straightforward. If $t_{i}^{*}=15000$, diffusion did not stabilize until the end of simulations and it is not necessarily clear whether one of the two technologies won the race. Technological variables evaluated at this point in time cannot be interpreted as performance thresholds. Some additional discussion how about alternative procedures how to deal with these irregularities in the data can be found in (Hötte, 2019d).

The variance $\left(\sigma_{i}^{\nu}\right)^{2}$ of the diffusion measure $\nu_{i, t}^{c} \in[0,1]$ is computed for each agent $i$ over the whole simulation horizon for each single simulation run. The variance is scaled by 100 because otherwise, it is numerically to small for a proper computational analysis and subject to rounding errors. Note that $\left(\sigma_{i}^{\nu}\right)^{2}$ is different from the standard deviation shown in the time series plots (e.g. Fig. $3 \mathrm{c}$ ) which is computed over a 2.5 year window.

Model selection procedure. The final model specification was chosen using a stepwise model selection procedure based on the Bayesian Information Criterion (BIC). This procedure is implemented in the $\mathrm{R}$ functions stepAIC() (stepGAIC() for Probit) (Venables and Ripley, 2002; Stasinopoulos et al., 2017). A full set of pairwise interaction terms of all explanatory variables was included in the input term for the stepwise model selection functions. The functions return the model specification that is associated with minimum BIC.

The OLS and Probit models were mainly chosen for reasons of simplification and ease of interpretation. A longer discussion of alternative functional forms that had been tested is available in Hötte (2019d).

Instrumental variable approach. In some of the regression models, a dummy variable that indicates whether a transition took place $\mathbb{1}(e c o)$ is included. Descriptive analysis of time series disaggregated by the type of regime exhibit very different patterns, not only with regard to the outcome, but also concerning 
the variation over time. This raises concerns about the possible endogeneity of emerging regime. The type dummy may be subject to reverse causation and may be correlated with the error term. These concerns are addressed using an instrumental variable approach (IV). Similar as before, the set of instruments and explanatory variables for the type dummy are identified using an iterative BIC based model selection procedure and ensuring that the number of instruments exceeds the number of explanatory variables in the second stage regression.

To determine the set of instruments, a heuristic procedure based on a repeated BIC based model selection procedure was used. The model selection procedure was performed separately at the first and second stage of the regression using fitted type dummies as input at the second stage. All variables that were excluded by the BIC on the second stage were included as instrument on the first stage. The selection procedure is rather a heuristic, but not analytically justified approach. It roughly ensures that the instrument is not or only weakly related to the dependent variable in the second stage regression. Additional information is available in Hötte (2019d).

Transition boundaries. A K-nearest neighbors clustering algorithm with a given number of nearest neighbors was used to train the classification model that is used to draw the transition boundary. This was made by the use of the knn3() function of the R-package caret (Kuhn, 2018). The appropriate number of nearest neighbors depends on the sample size and affects the smoothness of the curve, but there is no analytical rule to determine the optimal number. Here, 25 neighbors were used for macroeconomic data. The decision on the number was based on a series of trials with different parameters. It was found that the results are robust across different, non-extreme specifications. The final decision is mainly based on aesthetic reasons, i.e. the boundaries are relatively smooth.

The plots in the article show the transition boundaries in the space of initial diffusion barriers (Fig. 4). Colors indicate the final regime type. For the training of the classification algorithm, initial barriers were used to predict the type of the resulting technological regime.

Transparency and reproducibility. The simulation model, all data and programming code that was used for the simulation and statistical evaluation of simulated data is available online as a separate data publication (Hötte, 2019a). The data publication also contains additional descriptive statistics, figures and additional statistical tests using alternative model specifications and data processing procedures. The reader is also referred to the accompanying working paper (Hötte, 2019d). For this article, some additional analyses were made that are not included in the data publication. These are available upon request. 